\title{
Las inasistencias al trabajo como causa de terminación del contrato*
}

\author{
Pedro Irureta Uriarte**
}

\begin{abstract}
RESUMEN
Dentro de las causas de despido disciplinario, el Derecho chileno probibe las inasistencias injustificadas del trabajador durante determinados dias del mes, de forma que la gravedad de la infracción se verifica en la reiteración de una ausencia que frustra los objetivos del contrato. Dicha reiteración ha sido cuantificada previamente por el legislador, a objeto de responder al test de gravedad que supone la falta. Si bien es cierto que la indicación precisa del número de inasistencias y limita el libre arbitrio del juzgador en la calificación del incumplimiento, en la práctica la jurisprudencia ha centrado su actividad en determinar el alcance de la justificación, observándose al efecto una mirada más flexible que pone el acento en la sensatez del caso y en la racionalidad del impedimento.
\end{abstract}

Inasistencia - abandono - extinción del contrato

The absence to work as a cause of termination of contract

\begin{abstract}
Within the grounds for disciplinary dismissal, Chilean law probibits unexcused absences of the employee during certain days of the month so that the gravity of the offense takes place in the reiteration of an absence that frustrates the objectives of the contract. Such reiteration has been quantified by the legislator, with the objective of responding to the seriousness test that the infraction implies. While it is true that the precise details of the number of absences limits the discretion of the judge in the qualification of the offense, in reality the courts bave focused their decisions in determining the extent of the justification, showing a more flexible standpoint that stresses the reasonableness of the case and the rationality of the impediment.
\end{abstract}

Employment absenteeism - contract abandonment - termination of contract

* Abreviaturas: AFDO (Anuario de la Facultad de Derecho de Ourense); AL (Actualidad Laboral); CAP (Corte de Apelaciones); CC (Código Civil); CS (Corte Suprema); CT (Código del Trabajo); GJ (Gaceta Jurídica); RDJ (Revista de Derecho y Jurisprudencia y Gaceta de los Tribunales); RFM (Revista Fallos del Mes); RIT (Revista Internacional del Trabajo); RMCH (Revista Médica de Chile); RPS (Revista de Política Social); SEC (Sección).

** Abogado, Doctor en Derecho, Profesor Titular de Derecho del Trabajo de la Universidad Alberto Hurtado, Santiago de Chile. Correo electrónico: piruret@uahurtado.cl

Artículo recibido el 30 de agosto de 2013 y aceptado para su publicación por el Comité Editorial el 28 de octubre de 2013. 


\section{INTRODUCCCIÓN}

$\mathrm{D}$ esde las primeras regulaciones normativas del fenómeno laboral, el legislador chileno ha venido incorporando los supuestos de inasistencia como una causa típica de despido disciplinario. Este marco regulatorio ha partido de la base que resulta imposible llevar adelante la prestación si el sujeto deudor de trabajo no está a disposición del empleador. Por ello se ha tenido que distinguir claramente las ausencias fundadas en una causa justificada, de aquellas que carecen de dicha justificación. Este último tipo de inasistencia se encuentra en la actualidad consagrado como un supuesto especial de infracción, y desde luego su expresión más elocuente se encuentra en el artículo $160 \mathrm{~N}^{\circ} 3 \mathrm{CT}$. En efecto, el mencionado precepto legal señala que el contrato de trabajo termina, sin derecho a indemnización alguna, por: "3.- No concurrencia del trabajador a sus labores sin causa justificada durante dos días seguidos, dos lunes en el mes o un total de tres días durante igual período de tiempo; asimismo, la falta injustificada, o sin aviso previo de parte del trabajador que tuviere a su cargo una actividad, faena o máquina cuyo abandono o paralización signifique una perturbación grave en la marcha de la obra" 1 .

Como se ha dicho, la configuración de las inasistencias injustificadas como un supuesto clásico de causal disciplinaria se remonta a las primeras leyes sociales; y su estructura se ha mantenido prácticamente inalterada durante todo el proceso de desarrollo del Derecho del Trabajo en Chile (más allá de las modificaciones puntuales que haya experimentado en su terminología o ubicación $)^{2}$. Así, por ejemplo, el artículo $5^{\circ}$, numerales 10) y 11), de la Ley $\mathrm{N}^{\circ} 4.053$ (de 1924), establecía que el contrato de trabajo terminaba por "dejar el obrero de concurrir al trabajo durante dos días consecutivos, sin causa justificada"; o bien por "abandono del trabajo de parte del obrero". Esta redacción inicial fue mantenida, y en parte complementada, por el Código del Trabajo de 1931, cuyo artículo $9^{\circ} \mathrm{N}^{\circ} 10$ determinó que el contrato de trabajo terminaba: "Por no concurrir el obrero al trabajo, sin causa justificada, durante dos días seguidos, dos lunes en el mes o un total de tres días durante igual periodo de tiempo". Del mismo modo, el Código de 1931 mantuvo la hipótesis del abandono que ya consagraba la Ley $\mathrm{N}^{\mathrm{0}} 4.053$, pero especificó dentro de esta figura la "falta injustificada o sin aviso previo, de asistencia al trabajo de parte del obrero que tuviere a su cargo una faena o máquina cuyo abandono o paralización signifique una perturbación en la marcha del resto de

${ }^{1}$ No es la única hipótesis extintiva que sobre esta materia regula el Código. También existen sanciones para las salidas intempestivas del trabajo o la negativa a prestar servicios sin causa justificada (Art. $160 \mathrm{~N}^{\circ} 4$ CT). Asimismo, regulaciones de similar orientación se han consagrado en el caso del contrato de embarco a cuyo efecto el artículo 120 CT dispone que "ninguna persona de la dotación de una nave podrá dejar su empleo sin la intervención de la autoridad marítima o consular del puerto en que se encuentra la nave”.

${ }^{2}$ Referencias semejantes a esta causal de despido se encuentran en otros ordenamientos de nuestro entorno. Por ejemplo, el artículo 47, apartado X, de la Ley Federal del Trabajo de México, y el artículo 54.2, letra a), del Estatuto de los Trabajadores español. 
la obra”" . Una norma similar se consagró también en el artículo 164 del Código de 1931, ahora en relación con la terminación del contrato de los empleados. Según dicha norma, era causal de caducidad el "abandono del empleo por dos días consecutivos, sin causa justificada”. Como se puede observar, la actual norma del artículo $160 \mathrm{~N}^{\circ} 3$ CT mantiene una redacción muy similar a la contenida en las primeras leyes sociales y su núcleo definitorio ha logrado sobrevivir a un conjunto de reformas, de muy diverso orden e intensidad.

La explicación para este proceder, históricamente aceptado, se encuentra en la estructura del vínculo laboral. Todo contrato de trabajo lleva envuelta una cláusula obvia en orden a que el trabajador concurrirá al ámbito organizativo de su empleador, a objeto de cumplir las labores con la periodicidad pactada. Si no se ejecuta esa mínima obligación por parte del trabajador, el objeto del contrato se ve frustrado, y el prestador del servicio incurre en mora provocando de paso eventuales perjuicios al empleador ${ }^{4}$. Dicho incumplimiento deja al descubierto además un desequilibrio en las prestaciones recíprocas y también afecta la eficacia productiva de una empresa así como la pérdida de la actividad potencial del ausente ${ }^{5}$. Desde esta perspectiva, el fundamento de la causal se encuentra en la circunstancia de que el trabajo convenido no se está realizando, razón por la que no se cumple el objeto del contrato ${ }^{6}$, cuestión que frustra la primera y más básica de las obligaciones del vínculo, cual es que el trabajador ejecute sus labores durante la jornada convenida ${ }^{7}$.

A lo anterior habría que agregar que la celebración del vínculo laboral implica un deber inicial del trabajador en orden a cumplir diligentemente las obligaciones pactadas, lo que se concreta en la obligación de dar en su trabajo el rendimiento propio o normal de un deudor laboral ${ }^{8}$. Por ello, en el ámbito de las relaciones de trabajo lo que se exige es una diligencia objetiva vinculada a la obtención de un rendimiento que permita satisfacer el interés de la contraparte. Pues bien, si se producen inasistencias injustificadas entonces el trabajador infringe el deber de diligencia y termina afectando la disciplina de la empresa?.

${ }^{3}$ Artículo $10 \mathrm{~N}^{\mathrm{o}}$ 11, letra c), del Código del Trabajo de 1931. Si bien en el Código de 1931 esta infracción estaba incrustada como un supuesto especial de abandono por parte de los obreros, fue la Ley $\mathrm{N}^{\circ} 16.455$ la que aglutinó ambos tipos de infracciones en un solo numeral (artículo $2^{\circ} \mathrm{N}^{\circ} 6$ ).

${ }^{4}$ Cfr. artículos 1551 y 1552 CC.

${ }^{5}$ Cfr. Behrend, H., "La ausencia voluntaria del trabajo", RIT Vol. LIX (1959), p. 149.

${ }^{6}$ Vid. Aguilera Izquierdo, R., Las causas del despido disciplinario y su valoración por la jurisprudencia, Aranzadi, Pamplona 1997, p. 240.

${ }^{7}$ Cfr. Delgado Ucelay, I., "Faltas repetidas e injustificadas de asistencia al trabajo", Estudios sobre el despido disciplinario, Acarl, Madrid 1992, p. 125. Vid. también García Murcia, J., "Falta de diligencia y transgresión de la buena fe contractual" (I y II), AL N 25, p. 279.

${ }^{8}$ Cfr. por todas sentencia de la CAP de Concepción de 6 de septiembre de 2002. GJ N 267 (2007), p. 191. En el plano doctrinal vid. además Alonso Olea, M., El despido, Instituto de Estudios Políticos, Madrid 1958, p. 140.

${ }^{9}$ Cfr. Montoya Melgar, A., Derecho del Trabajo. Tecnos, $29^{\text {a }}$ edición, Madrid 2008, p. 461. 
En el Derecho del Trabajo chileno, el núcleo definitorio de las causas de despido no ha sido especialmente analizado por la doctrina. Ello ha supuesto relegar la determinación de los contornos de la mayoría de las causales a una fructífera elaboración jurisprudencial. Teniendo en cuenta lo anterior, en el presente artículo se analizan los supuestos de ausencia que son propios del artículo $160 \mathrm{~N}^{\circ} 3 \mathrm{CT}$, poniendo énfasis en el alcance que la jurisprudencia le ha otorgado a cada una de las hipótesis que relata la parte primera de dicho precepto. Con todo, en este estudio se han excluido expresamente los casos de ausencia injustificada por parte de aquel que tiene a su cargo una actividad, faena o máquina relevante toda vez que en rigor ello corresponde a supuestos más propios del abandono. En efecto, la primera parte del artículo $160 \mathrm{~N}^{\circ} 3 \mathrm{CT}$ pretende sancionar el absentismo relevante de duración acotada, que no llega a constituir abandono (al menos como una declaración tácita de renuncia). En el segundo caso, el Código sanciona no tanto la duración de la inasistencia, sino que esencialmente las consecuencias que ello provoca en atención a que el trabajador tenía a su cargo una actividad, faena o máquina relevante.

\section{LA CONFIGURACIÓN DE LOS TIPOS DE INASISTENCIA}

El tipo infraccional al que se refiere el artículo $160 \mathrm{~N}^{\circ} 3 \mathrm{CT}$ es la inasistencia; es decir, la no concurrencia del trabajador a sus labores en el lugar que se ha designado en el contrato o bien que se ha acordado con el empleador. Excepcionalmente, parte de la doctrina, sobre todo comparada, ha pretendido asimilar estos supuestos a aquellas figuras de total inactividad del trabajador durante la jornada de trabajo ${ }^{10}$ o bien cuando el trabajador no asiste a clases estando obligado a ocupar parte de su jornada en promoción o formación profesional ${ }^{11}$. No obstante, en el Derecho chileno esa hipótesis ha sido rechazada por la jurisprudencia nacional, la que ha separado la inactividad dentro de la jornada de los casos más propios de ausencia laboral ${ }^{12}$. Por lo demás, ha sido el propio legislador quien claramente ha deslindado los supuestos de inactividad (artículo 160 $\mathrm{N}^{\mathrm{o}} 4 \mathrm{CT}$ ) de aquellos que implican ausencia sin causa justificada. La única salvedad a esta separación temática puede encontrarse, en términos puntuales, en la segunda parte del artículo $160 \mathrm{~N}^{\circ} 3 \mathrm{CT}$. En dicha norma, la falta injustificada o sin aviso previo de una

${ }^{10}$ Vid. Aguilera Izquierdo, cit., p. 242: "La falta de asistencia supone, por tanto, la ausencia total o la asistencia deliberadamente inactiva (...)"; y Gómez Abelleira, F. J., "Las causas disciplinarias del despido", en Sempere Navarro A. V. (director), El despido, Aranzadi-Thomson Reuters, $2^{a}$ edición, Pamplona 2009, p. 175: "La falta de asistencia equivale a la ausencia de trabajo en la jornada diaria determinada (...). (También) se ha considerado como tal mera presencia física del trabajador en su puesto pero sin desempeño de labor alguna”.

${ }^{11}$ Cfr. Delgado Ucelay, cit., p. 126.

12 Vid. por todas sentencia de la CS de 28 de agosto de 1998. RFM No 466 (1997), p. 1675: “Asimismo, la ausencia a trabajar no es sinónimo de negativa a trabajar"; y sentencia de la CAP de San Miguel de 24 de noviembre de 1982. RDJ T. LXXIX, sec. tercera (1982), p. 150: “(..) la renuencia a realizar tal actividad implica abandono de trabajo configurado por la negativa a trabajar sin causa justificada en las faenas convenidas en el contrato de trabajo (...)". 
máquina, faena o actividad tiende a incorporar los actos de contumacia consistentes en no asumir las tareas relevantes que le corresponden al trabajador.

Las inasistencias, en todo caso, son distintas del mero abandono del trabajo ${ }^{13}$. Esta última figura se estructura mediante el acto voluntario y unilateral del trabajador constitutivo de incumplimiento, y por el que se extingue el contrato de trabajo ${ }^{14}$. Desde esta perspectiva, en el abandono hay una clara intención de hacer dejación del cargo, cuestión muy distinta de las meras inasistencias en que lo que subyace en la conducta es una falta de diligencia que trae envuelto el absentismo.

\section{Las inasistencias injustificadas durante dos días seguidos, dos lunes en el mes o un total de tres dias durante igual tiempo}

Como se ha dicho, el artículo $160 \mathrm{~N}^{\circ} 3$ CT sanciona en primer lugar la acumulación de inasistencias diarias durante determinados períodos. Se trata de una típica figura sancionadora del absentismo, entendiendo por este la circunstancia de que en determinados días o períodos, "en que es debida la prestación laboral, el trabajador no la realiza por no asistir o por haber estado ausente del puesto de trabajo"15.

En la hipótesis extintiva a la que se hace referencia es el propio legislador quien se ha encargado de circunscribir el ilícito: la inasistencia es relevante cuando se acumula durante dos días seguidos, o durante dos lunes en el mes o tres días en el mismo período. Es decir, debe tratarse de inasistencias reiteradas cuyo quantum el Código se encarga de establecer a priori. La reiteración deja en evidencia, además, la continuidad y contumacia de la conducta prohibida ${ }^{16}$, cuestión que el legislador termina considerando inaceptable desde el punto de vista de las obligaciones contractuales.

La reiteración de la conducta infraccional queda al descubierto al exigirse inasistencias continuas, ya sea que se trate de días seguidos, o de ciertos días en el mes. Dicha reiteración responde al test de gravedad de la infracción ${ }^{17}$, cuestión que evidentemente el legislador ha preferido cuantificar desde ya. La indicación precisa del número de inasistencias es un factor de certeza jurídica, toda vez que, a diferencia de otras experiencias comparadas, el

${ }^{13}$ Cfr. sentencia de la CS de 22 de julio de 1991. Repertorio de Legislación y Jurisprudencia Chilenas. Código del Trabajo y Leyes Complementarias, T. I. Editorial Jurídica de Chile, Santiago 2002, p. 12. Vid. también sentencia de la CAP de Santiago de 17 de abril de 1991. RDJ T. LXXXVIII, sec. tercera (1991), p. 36.

${ }^{14}$ Cfr. Montoya Melgar, Derecho, cit., p. 457 . Vid. también Gómez Abelleira, F. J., La causalidad del despido disciplinario, Civitas/Thomson Reuters, Madrid 2009, p. 135.

${ }^{15}$ Vid. Briones González, C., La extinción del contrato de trabajo por causas objetivas. Centro de Publicaciones Ministerio de Trabajo y Seguridad Social, Madrid 1995, p. 301.

${ }^{16}$ Cfr. Durán López, F., "La prescripción de las faltas de asistencia o puntualidad del trabajador tras la Ley de Relaciones Laborales", RPS N 117 (1978), p. 252. Vid. también Gárate Castro, J., "Las faltas de asistencia o puntualidad como incumplimiento contractual justificativo de despido disciplinario", RPS No 129 (1981), p. 209; Fernández López, M. F., El poder disciplinario en la empresa, Civitas, Madrid, 1991, p. 200; y González Ortega, J., "Faltas de asistencia o puntualidad al trabajo; la repetición de las faltas y la aplicación del principio non bis in idem”. RPS No 139 (1983), p. 251.

17 Vid. Montoya Melgar, Derecho, cit., p. 471. 
juzgador no tiene un libre arbitrio para calificar la ocurrencia de la causal (al menos en lo que se refiere al número de inasistencias necesarias para configurar el ilícito). Por el contrario, en el caso chileno, el Código es preciso para calificar el incumplimiento y es justamente en la reiteración donde radica la gravedad, ya que una inasistencia casual o aislada no es, al menos en principio, merecedora de sanción extintiva por sí misma. Más aún, nótese que el artículo $160 \mathrm{~N}^{\circ} 3$ CT no exige una infracción anterior para configurar la causal, razón por la que la ocurrencia de una hipótesis infraccional ya constituiría fundamento suficiente para poner término al contrato.

La gravedad de la inasistencia injustificada se produciría, a mayor abundamiento, por la mera repetición de la falta en los término indicados por el legislador, sin que sea necesario que el empleador se someta a un sistema de graduación de las infracciones aplicando sanciones de menor entidad que el despido (dependiendo si se trata de la primera infracción o de la última de una serie de ellas) ${ }^{18}$. Con todo, alguna corriente comparada ha puesto en evidencia la necesidad de que este tipo de causales no sean invocadas como causas objetivas que deban aplicarse automáticamente, sino que la inasistencia debe ser evaluada en relación con las circunstancias concurrentes en cada caso específico ${ }^{19}$. En el caso chileno, no obstante, esa alternativa ha quedado radicada en la calificación judicial de la eventual justificación de la ausencia; pero no en la determinación del número de ausencias necesario para configurar la causal.

\subsection{La falta de justificación de la conducta}

El tipo infraccional sancionado por el Código es la inasistencia, sin justificación, durante un tiempo determinado. La justificación permite resolver el test de culpabilidad de la conducta infraccional, y le exige al trabajador que fundamente las razones de la inasistencia antes del despido ${ }^{20}$. Por cierto, dicha justificación debe analizarse en su propia realidad $^{21}$.

La figura reconduce a un absentismo que el legislador no considera digno de protección jurídica y por eso permite la extinción del contrato sin derecho a indemnización. En ese esquema, al empleador le corresponderá acreditar la ausencia fundamentalmente mediante la exhibición del libro de asistencia u otra prueba suficiente. Al trabajador, por su parte, le tocará acreditar que la ausencia se encuentra justificada ${ }^{22}$.

${ }^{18}$ Cfr. Gárate Castro, cit., pp. 207 y 208.

${ }^{19}$ Cfr. Aguilera Izquierdo, cit., p. 248: "La gravedad depende no solo del número de faltas cometidas, sino también de los efectos que derivan del incumplimiento del trabajador atendiendo a las circunstancias del caso". Vid. también Gil Plana, J., "Las faltas repetidas e injustificadas de asistencia o puntualidad al trabajo como causa de extinción de los contratos”, AL No 1 (2005), p. 1482.

${ }^{20}$ Vid. Montoya Melgar, Derecho, cit., p. 471.

${ }^{21}$ Cfr. Gárate Castro, cit., p. 212.

${ }^{22}$ Cfr., entre otras muchas, sentencia de la CS de 8 de mayo de 1997. RFM N 462 (1997), p. 764; sentencia de la CS de 21 de agosto de 1997. RDJ T. XCIV, sec. tercera (1997), p. 121; sentencia de la CS de 04 de diciembre de 1997. RDJ T. XCIV sec. tercera (1997), p. 202; sentencia de la CS de 6 de abril de 1998. RDJ T. XCV, sec. tercera (1998), p. 40; sentencia de la CS de 27 de mayo de 2004. RDJ T. CI, sec. 
Como se ha encargado de recalcar la jurisprudencia ${ }^{23}$, la expresión "sin causa justificada" no ha sido definida legalmente debiendo por ello acudirse al sentido natural y obvio de las palabras que la integra, contexto en el que estas se orientan a la existencia de una razón o motivo suficiente que determina que la ausencia del dependiente a sus labores resulta del todo aceptable, convenciendo plenamente sobre la necesidad que originó la falta respectiva. Debido a la severidad con que la ley sanciona la inexcusabilidad en la materia, "la razonabilidad de los acontecimientos se erige como imprescindible, a la luz de lo que la doctrina ha denominado la 'sensatez del caso' y cuya amplitud abarca una multiplicidad de situaciones con un denominador común, cual es la amenidad en su gestación en relación al afectado" 24 .

La exigencia de este requisito obliga a distinguir desde ya la voluntariedad de la conducta de la exigencia de justificación de la misma. Si se analiza con detención, el Código no hace referencia a la circunstancia de la voluntariedad de la ausencia, poniendo el énfasis exclusivamente en la justificación. Y ello tiene su razón de ser en el hecho de que una inasistencia perfectamente puede ser de carácter involuntario, pero no por ello deja de ser injustificada. Piénsese, por ejemplo, en el caso de un trabajador que eventualmente comete un delito y que en razón de ello es detenido: su inasistencia

tercera (2004), p. 64; sentencia de la CAP de Concepción de 23 de junio de 2003. GJ N 279 (2003), p. 212; sentencia de la CAP de Concepción de 11 de julio de 2001. RFM N 502 (2000-2002), p. 2828; sentencia de la CAP de Valparaíso de 29 de mayo de 2001. RFM N 502 (2000-2002), p. 2802; sentencia de la CAP de Santiago de 10 de enero de 1991. RDJ T. LXXXVIII (1991), p. 24; sentencia de la CAP de Santiago de 27 de junio de 1983. RDJ T. LXXX, sec. tercera (1983), p. 97; y sentencia de la CAP de San Miguel de 23 de septiembre de 1981. RDJ T. LXXVIII, sec. tercera (1981), p. 139.

${ }^{23}$ Cfr., entre otras, sentencia de la CS de 24 de enero de 2006. RDJ T. CIII, sec. tercera (2006), p. 225; sentencia de la CS de 29 de noviembre de 2005. RFM N 539 (2005-2006), p. 3149; y sentencia de la CAP de Concepción de 13 de octubre de 2000. RDJ T. XCVII, sec. tercera (2000), p. 184.

${ }^{24}$ Sentencia de la CS de 28 de julio de 2010. RFM No 554 (2010), p. 513 . En igual sentido, sentencia de la CS de 2 de junio de 2009 (Causa Ingreso Corte $N^{\circ}$ 1673-2009): "Este precepto utiliza las expresiones 'causa justificada', las que no han sido definidas por el legislador laboral, de manera que ha de buscarse su adecuada interpretación a la luz del uso común de las mismas palabras y de los principios generales del derecho, aplicables en la especie. Al respecto cabe señalar que la palabra causa se corresponde con origen o fundamento, con motivo o razón, y justificación, con el efecto de justificar, es decir, con probar algo con exactitud, rectitud y verdad"; sentencia de la CS de 24 de enero de 2006. RDJ T. CIII, sec. tercera (2006), p. 225: "Las expresiones 'causa justificada' no han sido definidas por el legislador, de manera que ha de determinarse su adecuada interpretación a la luz del uso común de las mismas palabras y de los principios generales del derecho. Si bien es cierto que las causas que podrían llegar a constituir una justificación para la inasistencia del trabajador a sus labores habituales no están señaladas de manera específica en la ley, tampoco existe un precepto que exija su consagración expresa en ella. Por consiguiente, habrá justificación cuando el trabajador invoque un motivo digno de ser atendido racionalmente para no concurrir a sus labores (...)"; sentencia de la CS de 7 de enero de 1982. RDJ T. LXXIX, sec. tercera (1982), p. 1: “(...) por el vocablo justificado debe entenderse lo que está conforme a la justicia y razón o que obra según justicia y razón”; y sentencia de la CAP de Concepción de 13 de octubre de 2000. RDJ T. XCVII, sec. tercera (2000), p. 184: "La ley no ha definido ni regulado qué ha de entenderse por causa justificada, por lo que podrá consistir en cualquier hecho que, atendida su naturaleza o entidad, haga imposible al trabajador concurrir a su trabajo (...)”. En el plano doctrinal, vid. además Gamonal Contreras, S., y Guidi Moggia, C., Manual del contrato de trabajo. AbedeloPerrot/LegalPublishing 2a edición, Santiago 2011, p. 284: "Por causa justificada entenderemos los motivos que permiten excusar la falta del trabajador a la luz de la razonabilidad y sensatez del caso (...)”. 
al trabajo será involuntaria, pero esa condición no tiene por qué justificar la falta de concurrencia al empleo ${ }^{25}$.

Con todo, sobre el particular existen dos corrientes interpretativas. Una de ellas plantea que lo relevante en esta materia es que la no concurrencia sea "sin causa justificada"; es decir, que no exista precepto legal, reglamentario o circunstancias de indudable valor que disculpen la no asistencia ${ }^{26}$. Por lo tanto, la falta de voluntariedad en la conducta no sería lo relevante, ya que el legislador ha puesto hincapié en la justificación y no en su voluntariedad. Por el contrario, otra tesis argumentativa exigiría el elemento volitivo en la ocurrencia de la causal toda vez que la existencia de hechos independientes de la voluntad del trabajador, y de los cuales no sea en forma alguna culpable, lo eximirían de responsabilidad ${ }^{27}$. Entre estas dos posturas argumentales, se abre una tercera hipótesis: para aplicar la causal resultaría preciso la concurrencia tanto de la voluntariedad así como de la falta de justificación. Es decir, por una parte la conducta debe tener su origen en un acto voluntario del trabajador, y al mismo tiempo debe haberse ejecutado sin justificación alguna. De estas tres alternativas, la jurisprudencia reciente parece haberse inclinado por la primera, sobre todo en aquellos casos en que el origen de la ausencia radica en una detención llevada a cabo por autoridad competente ${ }^{28}$.

${ }^{25}$ Por el contrario, tampoco podría considerarse justificada la inasistencia cuyo origen se encuentra en la necesidad de sustraerse al cumplimiento de una orden de aprehensión dictada por autoridad competente. Ese fue el caso que resolvió en su época la sentencia de la CS de 24 de agosto de 1936. RDJ T. XXXIII, sec. primera (1936), p. 493, al indicar que no es causa justificada para abandonar el empleo, "la alegada por el empleado de que ha necesitado sustraerse al cumplimiento de una orden de aprehensión librada por un Juzgado del Crimen, pues ello equivaldría a amparar la desobediencia a un mandato emanado de legítima autoridad". Una tesis contraria puede consultarse en la sentencia de la CS de 2 de noviembre de 1999. RDJ T. XCVI, sec. tercera (1999), p. 225: “(...) el trabajador fue previsto de su libertad por orden de autoridad competente, circunstancia que no pudo resistir, de manera que la ausencia en la que incurrió resultó plenamente justificada. En consecuencia, el despido de que fue objeto el trabajador debe calificarse de injustificado, tanto más cuanto que fue absuelto de los cargos que se formularon en su contra y que motivaron su privación de libertad (...)". ; y sentencia de la CAP de Antofagasta de 7 de agosto de 1996. RDJ T. XCIII, sec. tercera (1996), p. 118, la que concluye que si bien "la inasistencia se produjo debido a la privación de libertad del trabajador, como consecuencia de un proceso por delito de giro doloso de cheque (...), hay que convenir que nadie quiere su privación de libertad, razón por la cual no podría concebirse que haya una persona que se ponga en este evento solo para (dejar de) concurrir a sus labores, por lo que habrá que también convenir, que se trata de una situación que es totalmente independiente de la voluntad de ella”.

${ }^{26}$ Vid. Aguilera Izquierdo, cit., p. 255. En igual sentido, Gárate Castro, cit., p. 212; y Rodríguez Rodríguez, E., "Las faltas de asistencia o puntualidad al trabajo como infracción disciplinaria: su regulación convencional”, AFDO No 1 (2006), p. 442.

${ }^{27}$ Vid. Aguilera Izquierdo, cit., p. 255. Ello ocurriría, por ejemplo, "cuando el trabajador sufre algún tipo de perturbación mental o enfermedad psíquica que excluye en él la libre determinación”. La exigencia de voluntariedad fue planteada, en su momento, por la sentencia de la CAP de Antofagasta de 7 de agosto de 1996. RDJ T. XCIII, sec. tercera (1996), p. 118, según ella, para aplicar la causal resulta indispensable que la inasistencia carezca de toda causa, de forma tal que ella se produce por la mera voluntad del trabajador, que libremente decide no concurrir a sus labores sin que haya alguna circunstancia externa ajena a él que lo lleve a adoptar tal decisión”.

${ }^{28}$ Vid. por todas sentencia de la CS de 17 de agosto de 2006. RFM No 536 (2005-2006), p. 2213. 
La justificación, en todo caso, debe estar respaldada. Cuando dicho respaldo se encuentra en una norma legal o reglamentaria, o bien en un permiso expreso del empleador, no existen mayores inconvenientes para explicar la ausencia; pero lo que no resulta admisible es que la justificación quede al puro arbitrio del trabajador ${ }^{29}$. El problema mayor, no obstante, se produce al momento de sopesar circunstancias relevantes que disculpen la inasistencia, ya que es una cuestión de hecho que corresponde calificar a los jueces del fondo, con el mérito que arrojen los antecedentes y la apreciación de las circunstancias en que se produce la inasistencia ${ }^{30}$. Por ejemplo, la jurisprudencia ha considerado justificada la ausencia en razón del fallecimiento de un familiar ${ }^{31}$, por existir enfermedad del cónyuge $\mathrm{e}^{32}$ o de un hijo ${ }^{33}$, por haber sufrido un cólico nefrítico que "obligó al trabajador a guardar reposo" ${ }^{4}$, cuando la inasistencia tiene su origen en un error del trabajador en cuanto al tiempo de extensión de una licencia ${ }^{35}$, cuando el trabajador falta por tener que cumplir trámites vinculados a la formalización de un

${ }^{29}$ Cfr. Gómez Abelleira, "Las causas disciplinarias”, cit., p. 184. En el plano jurisprudencial, vid. además sentencia de la CS de 1 de octubre de 1971. RDJ T. LXVIII, sec. tercera (1971), p. 75.

30 Vid. por todas sentencia de la CS de 23 de octubre de 1996. RDJ T. XCIII, sec. tercera (1996), p. 118; sentencia de la CS de 5 de septiembre de 2001. GJ No 255 (2001), p. 220; y sentencia de la CS de 29 de octubre de 2001. GJ No 256 (2001), p. 206.

31 Vid. en esta línea sentencia de la CS de 20 de mayo de 1992. GJ No 143 (1991), p. 110. Dicha sentencia confirmó el criterio adoptado tanto por el tribunal laboral como por la CAP de Santiago: "IV (...). b) que su ausencia en tales días se debió a que falleció un tío suyo en la zona del sur del país, viajando al velorio, dejando encargo a su hermana de avisar al empleador, quien no estimó suficiente la razón de tal ausencia, procediendo al momento de reincorporarse al trabajo el día jueves a confirmar el despido anunciado a quienes concurrieron a la empresa a dar aviso de la ausencia del actor; c) que en consecuencia, no se daban los presupuestos de la causal de caducidad del contrato invocada por la empleador, esto es ausencia injustificada y sin aviso".

${ }^{32}$ Cfr. sentencia de la CS de 29 de abril de 1968. RDJ T. sec. tercera (1968), p. 44. Una lógica similar se ha seguido en el Derecho comparado (vid. Gárate Castro, cit., p. 212): "si le concedieron permiso (por un día) para ausentarse e ir a ver a su esposa enferma, y al llegar... se encontró con que lo estaba de gravedad, es muy lógico, natural y humano que la acompañase hasta la desaparición del peligro”.

${ }^{33}$ Cfr. sentencia de la CS de 24 de enero de 2006. RDJ T. CIII, sec. tercera (2006), p. 225. Este caso jurisprudencial es muy ilustrativo de la posición mantenida por los tribunales, ya que el trabajador había solicitado anticipadamente a su empleador permiso para estar al lado de su hijo enfermo. Dicho permiso le fue denegado al trabajador, quien decidió unilateralmente faltar al trabajo y acompañar a su hijo de 1 año y 5 meses quien se encontraba hospitalizado por estar aquejado de una bronconeumonía. Al evaluar la situación, la Corte concluyó que existía "razón o motivo suficiente para que la demandante se haya encontrado impedida de cumplir con la obligación de asistencia que le imponía el contrato de trabajo”. Y agregó: "Noveno: Que no obsta a la conclusión anterior, que el Centro Asistencial, en que se encontraba hospitalizado el hijo de la demandante no contemplara, con carácter de indispensable y forzada, la permanencia de los padres, por cuanto, el solo hecho que un hijo se encuentre en las condiciones que estaba el de la demandante, la movían a ella a estar a su lado, independientemente de los requerimientos y reglamentos que al respecto tenía la entidad hospitalaria que en ese momento prestaba auxilios al menor".

${ }^{34}$ Cfr. sentencia de la CAP de Santiago de 26 de marzo de 1991. RDJ T. LXXXVIII, sec. tercera (1991), p. 30.

${ }^{35}$ Vid. sentencia de la CS de 4 de junio de 1998. RFM No 475 (1998), p. 903: "Se encuentra justificada la ausencia de una trabajadora, la que entendiendo encontrarse haciendo uso de licencia médica guardó reposo por el plazo en ella indicado, sin tener conocimiento de la reducción que de esta se había hecho por la Isapre”. 
contrato de promesa de venta de un inmueble de su dominio y que le sirve de vivienda ${ }^{36}$, cuando se asiste a la reunión del Consejo Regional de Valparaíso en representación de Isla de Pascua ("aun cuando el demandante no tuviera la autorización de su empleadora"37). En esta misma lógica, también debieran entenderse justificadas aquellas ausencias fundadas en el cumplimiento de deberes públicos o en la ejecución inexcusable de cargas de análoga naturaleza (v. gr., el servicio militar ${ }^{38}$. Incluso, se han llegado a validar las inasistencias cuyo origen se encuentra en un conflicto entre trabajador y empleador ${ }^{39}$. En síntesis, como señalan Thayer y Novoa, "cualquier situación no imputable al trabajador que denote un impedimento para el cumplimiento de la obligación de asistencia puede constituir justificación atendible" 40 .

\subsection{Supuestos justificantes de la inasistencia}

La redacción utilizada por la parte primera del artículo $160 \mathrm{~N}^{\circ} 3 \mathrm{CT}$, no exige que el trabajador dé aviso previo de la ausencia ${ }^{41}$; solo basta que este pruebe la justificación

${ }^{36}$ Cfr. Sentencia de la CS de 7 de enero de 1982. RDJ T. LXXIX, sec. tercera (1982), p. 1: "Es motivo justificado para no concurrir al trabajo (...) haberse dedicado el empleado (...) a realizar trámites para cumplir contratos de promesa de venta de un inmueble de su dominio, que le sirve de vivienda, y de promesa de compra de otro, destinado a su futura casa habitación, y a obtener el alzamiento de hipoteca y prohibición que le impedían efectuar la primera de dichas operaciones -ligada a la segunda-, existiendo aviso de la usencia al jefe directo, con anuncio de petición de permiso con cargo a feriado disponible, y sin que dicho jefe manifestara oposición".

${ }^{37}$ Cfr. sentencia de la CAP de Santiago de 19 de junio de 1995. RFM No 453 (1996), p. 1783.

${ }^{38}$ Cfr. Del Peso y Calvo, C., "Las faltas repetidas e injustificadas de puntualidad o de asistencia al trabajo como causa justa de despido". Dieciséis lecciones sobre causas de despido. Sección de Publicaciones e Intercambio, Facultad de Derecho Universidad de Madrid, Madrid 1969, p. 73.

${ }^{39}$ Cfr. sentencia de la CS de 25 de junio de 2001. GJ N 252 (2001), p. 185. Por el contrario, se ha estimado como injustificada la inasistencia (a pesar de existir controversia entre las partes sobre el lugar donde debían ejecutarse las labores) cuando el trabajador no se presentó a prestar servicios en otro establecimiento del empleador y que se encontraba ubicado en una ciudad diversa a aquella en que normalmente se ejecutaban las tareas (cfr. sentencia de la CS de 22 de julio de 2004. GJ N 289 [2004], p. 291). En todo caso, en este último supuesto el fundamento esgrimido por la Corte fue la circunstancia de que en el contrato de trabajo las partes habían pactado que el empleador estaba facultado "para modificar incluso la ciudad donde la demandante debía prestar sus servicios” (considerando sexto). La misma lógica se siguió en la sentencia de la CS de 1 de octubre de 1971. RDJ T. LXVIII, sec. tercera (1971), p. 75: "La negativa del trabajador para continuar en sus labores mientras no se le cambien las faenas que estaba desempeñando y para las cuales fue contratado, aduciendo para ello motivos de salud, constituye abandono de trabajo de su parte y es causa justificada de la terminación de su contrato, si de los autos no resulta comprobado que el patrón tenga otro trabajo disponible (...)".

${ }^{40}$ Vid. Thayer Arteaga, W., y Novoa Fuenzalida, P., Manual de Derecho del Trabajo, T. III. Editorial Jurídica de Chile, $3^{a}$ edición, 1998, p. 55. A nivel comparado, vid. además Gómez Abelleira, La causalidad, cit., p. 139, quien hace referencia a los "acontecimientos cuando menos preocupantes para el trabajador, que hace comprensible cierta desconsideración de las formalidades del ejercicio de los derechos”; y Delgado Ucelay, cit., p. 131 (quien sigue la tesis de Alonso García, M., Curso de Derecho del Trabajo. Ariel, 10ª edición, Barcelona 1987, p. 601): "Por justificación habrá de entenderse (...) la existencia de hechos independientes de la voluntad del trabajador, y de los cuales no sea en manera alguna culpable, que le impidan asistir al trabajo".

${ }^{41}$ Cfr. sentencia de la CS de 17 de mayo de 1991. RDJ T. LXXXVIII, sec. tercera (1991), p. 45. 
de las ausencias. Desde esta perspectiva, si la inasistencia es justificada, entonces el trabajador no hace más que ejercer un derecho a no prestar servicios ${ }^{42}$.

La justificación debe estar fundada en preceptos legales o reglamentarios, o bien en circunstancias de indudable valor que permitan eximir de responsabilidad al trabajador $^{43}$. Este último grupo de alternativas permite aceptar como justificante todos aquellos supuestos en que no existe responsabilidad del trabajador y que logren aprobar el denominado juicio de culpabilidad ${ }^{44}$. Este juicio admite ponderar judicialmente una variedad de supuestos de hecho que eventualmente le podrían restar gravedad a la conducta infraccional. Allí cabrían, por ejemplo, el estado anímico o sicológico del trabajador, la imposibilidad de regresar al país estando de viaje en el extranjero, la situación de crisis que genera en el trabajador una separación matrimonial, la muerte de un familiar, la enfermedad del cónyuge, o incluso "graves problemas personales o familiares que afecten al trabajador" ${ }^{45}$, entre otros varios supuestos.

Fuera de estas alternativas, se ha aceptado un conjunto de hipótesis que servirían de fundamento al absentismo aun cuando habrá que reconocer que la ley no define un catálogo expreso de alternativas que justifiquen la inasistencia ${ }^{46}$. Estas hipótesis constituyen lo que en doctrina se ha denominado como la causa impeditiva de la culpabilidad ${ }^{47}$, y que en definitiva permiten justificar la ausencia.

\subsubsection{La existencia de permisos legales o convencionales}

Los permisos son interrupciones causales y no periódicas de la prestación de servicios. Su fundamento se encuentra tanto en la ley como en la negociación colectiva o en el acuerdo individual ${ }^{48}$, y en términos generales podrían agruparse en tres categorías ${ }^{49}$ : en circunstancias relacionadas con la vida privada del trabajador (v. gr., matrimonio, fallecimiento de familiar o nacimiento de un hijo), las derivadas del desempeño por parte del trabajador de un deber público (v. gr., la participación inexcusable y personal en procesos electorales en calidad de miembro del colegio escrutador, o la realización

${ }^{42}$ Cfr. Briones González, cit., p. 292.

${ }^{43}$ Cfr. sentencia de la CS de 24 de enero de 2006. RFM No 530 (2005-2006), p. 3782: "Por consiguiente, habrá justificación cuando el trabajador invoque un motivo digno de ser atendido racionalmente, para no concurrir a sus labores, teniendo siempre presente si su intención afecta el cumplimiento de su contrato de trabajo”. En palabras de la doctrina nacional: “(...) habrá justificación cuando el trabajador ha tenido un motivo atendible, racionalmente hablando, para no concurrir a sus labores, teniendo siempre presente que, de suyo, no existe la intención de romper el contrato" (Thayer Arteaga y Novoa Fuenzalida, cit., p. 54).

${ }^{44}$ Cfr. Gómez Abelleira, "Las causas disciplinarias”, cit., p. 192.

45 Vid. Macchiavello Cúneo, G., Derecho del Trabajo T. I, Fondo de Cultura Económica, Santiago 1986, p. 520 .

46 Sentencia de la CS de 24 de enero de 2006. RFM No 530 (2005-2006), p. 3782.

47 Vid. Ortiz Lallana, M. C., "Causas y formas del despido disciplinario (en torno a los artículos 54 y

55)”, en El Estatuto de los Trabajadores veinte años después. Civitas, Madrid 2000, p. 1127.

48 Cfr. Gómez Abelleira, La causalidad, cit., p. 138.

${ }^{49}$ Vid. la clasificación de estas categorías en Briones González, cit., p. 335. 
del servicio militar) y aquellas que se derivan del ejercicio de funciones sindicales o de representación de personal (v. gr., los permisos a que se refiere el artículo 249 CT). Ciertamente, en todas aquellas hipótesis en que el propio legislador autoriza la ausencia no habría motivo para sancionar al trabajador. Igual conclusión puede extraerse en el caso de permisos convencionales: el trabajador se encuentra autorizado para no prestar servicios.

La inasistencia justificada se extiende, en todos estos casos, por el tiempo de duración del permiso (ya sea legal o convencional). Por ello, la jurisprudencia ha ratificado la validez de un despido cuando este tiene su origen en un uso excesivo de las autorizaciones. Así ocurrió, por ejemplo, con una trabajadora que gozaba de fuero maternal y que conocía la única fecha posible de regreso a la ciudad de Punta Arenas. Atendida la naturaleza y caracteres del pasaje adquirido por ella, y atendido además que la trabajadora conocía el fuero maternal que la amparaba y su fecha de término, la jurisprudencia estimó impropio que la demandante pudiese hacer valer la fuerza mayor para justificar sus ausencias "desde que, ciertamente, al comprar el pasaje respectivo tuvo conocimiento que no podía cambiar de fecha, ni devolverlo, lo que la obligaba a regresar varios días después de concluido su feriado legal, pero antes de expirar la protección maternal. Así, la demandante adoptó anticipadamente la decisión de regresar a sus labores con fecha posterior a la que legalmente debía hacerlo, una vez vencido su feriado (...), debiendo entonces asumir las consecuencias de sus actos, esto es, el despido efectuado por el empleador, sin que ahora pueda discutir la validez o ineficacia de esa desvinculación, atendido que la generó a sabiendas" 50 . Se trata de un criterio que, por lo demás, la propia jurisprudencia ya había esgrimido bajo la vigencia del Código de 1931, y que se ha mantenido prácticamente estable bajo las reformas posteriores ${ }^{51}$. En síntesis, durante los períodos de permiso legal o convencional el trabajador tiene un derecho que justifica plenamente su inasistencia. Vencido dicho período, nace un deber legal o contractual de reintegro.

\subsubsection{La existencia de enfermedad del trabajador}

Por regla general, las ausencias vinculadas a una enfermedad son estimadas como causas justificantes de la inasistencia (en el entendido que la enfermedad es de una entidad suficiente para dificultar la concurrencia del trabajador ${ }^{52}$ ). Como señaló en su momento

${ }^{50}$ Vid. sentencia de la CS de 27 de octubre de 2005. RFM No 538 (2005-2006), p. 2900 (en relación con la sentencia de la CAP de Concepción de 12 de noviembre de 2002). Sobre los problemas que plantea la fuerza mayor como causa de extinción del contrato, vid. además y por todos Montoya Melgar, A., "El despido por fuerza mayor", RPS No 85 (1970), pp. 95 y ss.

${ }^{51}$ Cfr., a modo de ejemplo, la sentencia de la CS de 24 de julio de 1944 . RDJ T. XLII, sec. primera (1944), p. 208: "Incurre en esta causal (...) el empleado que, después de vencido el permiso, no reasume sus labores sin acreditar impedimento legal alguno para no hacerlo".

52 Vid. en esta línea, sentencia de la CS de 17 de mayo de 1991. RDJ T. LXXXVIII, sec. tercera (1991), p. 48 (considerando sexto): "Que en tesis general una enfermedad justifica una ausencia; pero no se trata de una regla absoluta. Ello depende de la enfermedad y del modo como afecta a quien la sufre. Un simple 
la jurisprudencia, la enfermedad puede acreditarse por cualquier medio de prueba legal tanto testimonial como documental consistente esta última en certificados médicos, comprobantes de atención médica, licencias médicas y otros. "Así, el Comprobante de Atención Médica de Emergencia tiene pleno valor para justificar una enfermedad, a menos que se demuestre que no es verídico, lo que no ha acontecido en la especie" 53 . Solo por excepción, la misma jurisprudencia ha exigido que la enfermedad se acredite necesariamente mediante licencia ${ }^{54}$.

Sin perjuicio de lo anterior, el análisis de esta figura justificante de la ausencia obliga a distinguir entre los requisitos de fondo (vinculados a la situación que legalmente justifica el absentismo) y las exigencias formales de comunicación. En cuanto a lo primero, existe uniformidad en que la enfermedad del trabajador, debidamente certificada, justifica completamente la eventual inasistencia. Incluso se ha considerado justificada la ausencia en aquellos casos en que se produce rechazo a posteriori de la licencia o bien una reducción en la duración de la misma por parte del organismo de seguridad social que corresponda ${ }^{55}$. Con todo, una cosa es justificar la inasistencia y otra es comunicarla dentro de plazo al empleador ${ }^{56}$. Desde esta perspectiva, para que el impedimento justificante produzca efectos resulta preciso que la certificación sea debidamente tramitada, a objeto que el empleador pueda adoptar las medidas necesarias para organizar el trabajo ${ }^{57}$. Los problemas, por tanto, se producen cuando el trabajador no formalizó ante el empleador la respectiva licencia que lo habilitaba para ausentarse.

resfrío, por ejemplo, no legitima la ausencia”. Sobre las principales enfermedades que justifican el absentismo laboral vid., además, Mesa M., F. R., y Kaempffer R., A. M., “30 años de estudio sobre ausentismo laboral en Chile: una perspectiva por tipos de empresas”, RMCH Vol. 132 No 9 (2004), pp. 1100 y ss.

53 Vid. sentencia de la CS de 22 de octubre de 2003. RFM N 506 (2003), p. 5258. Cfr. también sentencia de la CS de 28 de julio de 2003. RFM N 512 (2003), p. 1806; sentencia de la CS de 13 de octubre de 2004. GJ N 292 (2004), p. 254; y sentencia de la CS de 15 de abril de 1996. RDJ T. XCIII, sec. tercera (1996), p. 39. A nivel doctrinario vid. además Thayer Arteaga y Novoa Fuenzalida, cit., p. 56.

${ }^{54}$ Vid. sentencia de la CAP de Valdivia de 13 de agosto de 1984. En Thayer Arteaga, W., y Rodríguez Alvarado, A., Código del Trabajo y Legislación Social, Editorial Jurídica de Chile/Editorial Jurídica Ediar ConoSur Ltda., Santiago 1988, p. 329: "La justificación invocada para el retraso, enfermedad, solo tiene un medio idóneo para acreditarse: la respectiva licencia médica (...), no bastando al efecto un simple certificado médico”.

55 Vid. sentencia de la CS de 30 de mayo de 2005. RFM N 533 (2005-2006), p. 1184, según ella, la "circunstancia que la Institución de Salud Previsional llamada a visar la licencia, haya rechazado el período de reposo fijado en ella por el profesional, por falta de antecedentes que justificaran ese reposo laboral, no puede alterar el hecho de que el trabajador se ausentó de sus funciones haciendo uso del beneficio por cuatro días de descanso, según la prescripción médica consignada en la licencia". Y agrega: "Undécimo: Que es dable entender que la duración del reposo señalado en la licencia por el profesional que la otorga tiene eficacia respecto del trabajador y de su ausencia laboral, de suerte que el rechazo de la licencia resuelto con posterioridad por la entidad que debe visarla no pueden privar de justificación a esa ausencia y dar lugar a la causal de terminación del contrato de trabajo prevista en el $\mathrm{N}^{\mathrm{o}} 3$ del artículo 160 del Código del Trabajo, en la medida que ella se produjo en ejercicio de un derecho". En igual sentido, sentencia de la CS de 30 de noviembre de 2000. RDJ T. XCVII, sec. tercera (2000), p. 234; sentencia de la CS de 29 de enero de 2004. RDJ T. CI, sec. tercera (2004), p. 4; sentencia de la CS de 8 de septiembre de 2004. GJ No 291 (2004), p. 207; y sentencia de la CAP de Concepción de 2 de abril de 1992. RDJ T. XC, sec. tercera (1993), p. 16;

${ }^{56}$ Cfr. sentencia de la CS de 17 de mayo de 1991. RDJ T. LXXXVIII, sec. tercera (1991), p. 45.

${ }^{57}$ Cfr. Delgado Ucelay, cit. 133. En igual sentido, Gárate Castro, cit., p. 213. 
Una parte de la jurisprudencia considera que el trámite de la comunicación es esencial y le ha restado valor a la licencia cuando esta es entregada fuera de plazo: "La actora, sin ser víctima de un imprevisto irresistible, no dio aviso previo de su ausencia a su empleador (...). No invalida el efecto del despido ni lo priva de fundamento el haber sido presentada la licencia tardíamente a su empleador" 58 . En el fondo, esta corriente jurisprudencial parte de la base que la comunicación extemporánea no justifica la inasistencia. ${ }^{59}$

Con todo, una amplia corriente doctrinaria y jurisprudencial plantea una mirada más flexible sobre la tramitación de las licencias así como de la debida comunicación al empleador. Y esta flexibilidad se apoya en la doctrina de la culpabilidad, lo que haría comprensible una mayor laxitud en el cumplimiento de las formalidades ${ }^{60}$. Si bien es cierto que la concesión de licencias médicas obliga al trabajador a comunicarla dentro de un plazo determinado, el incumplimiento de esta norma no es suficiente para justificar el despido ${ }^{61}$ (salvo que el trabajador realice actos que no se condicen con la razón

${ }^{58}$ Vid. sentencia de la CAP de Santiago de 21 de agosto de 1989. GJ N 131 (1991), p. 108. Vid. también sentencia de la CS de 28 de julio de 2010. RFM No 554 (2010), p. 513: "Octavo: Que sin embargo, la inexigibilidad de una conducta distinta por parte del dependiente más que la inconcurrencia a sus labores, conlleva, a propósito de la misma justificación en comento, el conocimiento de la circunstancia de que se trata por la empleadora. En efecto, sea que exista la noticia previa de la falta o esta no haya podido darse y el aviso haya sido contemporáneo a la misma, no es posible concebir o siquiera discutir la suficiencia de su motivación sin que el trabajador la comunique y haga presente, coetánea o posteriormente, acreditándola en caso de que ella le sea discutida por la empresa. Tal comprobación se explica, lógicamente, en una instancia que antecede el despido y que, por cierto, lo evita, sin perjuicio de que una vez suscitada la controversia de la real verificación del hecho pertinente, su involuntariedad o gravedad, la judicialización de la pertinencia del cese de servicios que ello provoque conducirá a un nuevo examen de la situación, ya dentro del marco del proceso laboral. Noveno: (...) al dar por justificada la ausencia de la actora el día 9 de junio de 2007, sin que fuera asentada la existencia de la comunicación de la misma ni su comprobación por algún medio a la demandada, los sentenciadores infringieron la norma del artículo $160 \mathrm{~N}^{\mathrm{o}} 3$ (...) toda vez que dichas circunstancias son parte integrante de la justificación de la ausencia, necesaria para que el dependiente eluda incurrir en la causal de caducidad, e importan, más allá de la mera noticia, acciones tendientes a explicar algo con razones convincentes, testimonios o documentos".

${ }^{59}$ Sentencia de la CS de 4 de diciembre de 2008. RFM No 550 (2008), p. 387. En dicho fallo, la Corte estimó que si bien en otras ocasiones se "ha reconocido la eficacia de la licencia médica como justificante de la inconcurrencia del beneficiado a sus labores (...), lo ha sido precisamente en casos donde el dependiente la ha presentado en tiempo y forma, siéndole desconocida subsiguientemente por la empleadora respecto de los períodos rechazados, posteriormente, en el ámbito administrativo. Se ha entendido, entonces, que la falta se produjo en el ejercicio de un derecho, al margen de que, finalmente, pueda generar el pago de un menor subsidio, por ejemplo". Un criterio similar puede observarse en los comentaristas del Código del Trabajo de 1931 (vid. por todos Edwards Izquierdo, I., Deberes del empleador frente al empleado. Ediciones Ercilla, Santiago, 1939, p. 235): el "empleado enfermo que no hiciese valer dentro de las 24 horas la justificación a que se alude, no podrá alegarla con posterioridad (...)”.

${ }^{60}$ Cfr. en la doctrina comparada Gómez Abelleira, "Las causas disciplinarias", cit., p. 179; y Cabanellas, G., Tratado de Derecho Laboral, T. II Vol. 3, Heliasta, $3^{a}$ edición, Buenos Aires 1988, p. 167. En el plano de la doctrina nacional, vid. además Lizama Portal, L., Derecho del Trabajo, LexisNexis, Santiago 2003, p. 178; Rojas Miño, I., Manual de Derecho del Trabajo, Lexis Nexis, Santiago 2004, p. 251; y Walker Errázuriz, F., Derecho de las Relaciones Laborales, Editorial Universitaria, Santiago 2003, p. 407.

${ }^{61}$ Cfr. Gómez Abelleira, "Las causas disciplinarias", cit., p. 182. En el plano jurisprudencial, vid. sentencia de la CS de 13 de octubre de 2004. GJ No 292 (2004), p. 254: "Quinto: (...) esta Corte ha decidido reiteradamente que el incumplimiento relativo a la presentación de la licencia médica por el trabajador dentro 
alegada para la ausencia, como trabajar para terceros durante una presunta enfermedad o entregar antecedentes clínicos falsos) ${ }^{62}$.

Conviene recalcar, en todo caso, que si se ha producido una enfermedad que, aun cuando no se encuentra certificada médicamente, ha sido aceptada por el empleador como justificante de la inasistencia, entonces en la especie se prefigura un permiso y el trabajador ciertamente que goza de un derecho para ausentarse ${ }^{63}$.

\subsubsection{La detención}

La privación de libertad de un trabajador, por acto de autoridad, ciertamente que afecta la concurrencia física del trabajador a sus labores. Desde luego, el hecho mismo de la detención será -salvo rarísimas excepciones- de carácter involuntario ${ }^{64}$, cuestión que permite distinguir la falta de justificación con la involuntariedad de la no asistencia. Dicha distinción ha sido implícitamente recogida por el artículo $160 \mathrm{~N}^{\mathrm{o}} 3 \mathrm{CT}$, el que solo exige que la ausencia sea "sin causa justifica". Lo anterior, obliga a evaluar la naturaleza de la detención ${ }^{65}$.

Una primera corriente jurisprudencial y doctrinaria ha partido de la aplicación estricta del principio de presunción de inocencia, en el sentido que una privación de libertad solo puede dar lugar a la suspensión del contrato de trabajo, pues hasta que no se acredite la culpabilidad el trabajador goza de la garantía vinculada a la referida presunción. Desde esta perspectiva, una detención que no está respaldada en sentencia condenatoria no sería suficiente para acreditar culpabilidad ${ }^{66}$. Y más aún, el trabajador justificadamente puede acreditar que su inasistencia se debió a un hecho no imputable a él ${ }^{67}$. Incluso, se ha llegado a sostener que la "detención y posterior procesamiento por

de plazo o, bien que esta contenga algún defecto de carácter formal, o si solo se acompaña un certificado médico para justificar la inasistencia del trabajador, no obsta a que el despido sea declarado injustificado, por cuanto la sanción que dichas omisiones pueden acarrear al actor pueden ser otras de carácter administrativas, tales como la falta de pago de la licencia médica por incumplimiento de los requisitos formales, pero en ningún caso pueden llevar a concluir que el trabajador no justificó su inasistencia (...)”. En igual sentido, vid. sentencia de la CS de 14 de marzo de 2007. RFM N 543 (2007), p. 504; sentencia de la CS de 27 de abril de 2004. RDJ T. CI, sec. tercera (2004), p. 44; sentencia de la CS de 13 de junio de 2002. GJ N 264 (2002), p. 184; sentencia de la CS de 30 de enero de 2002. GJ No 259 (2002), p. 159: sentencia de la CAP de Concepción de 13 de octubre de 2000. RDJ T. XCVII, sec. tercera (2000), p. 184; y sentencia de la CAP de Santiago de 9 de abril de 1986. RDJ T. LXXXIII, sec. tercera (1986), p. 59;

${ }^{62}$ Cfr. Delgado Ucelay, cit., p. 133. Vid. también Rodríguez Rodríguez, cit., p. 445.

${ }^{63}$ Cfr. Gómez Abelleira, "Las causas disciplinarias”, cit., p. 178.

${ }^{64}$ Cfr. Del Peso y Calvo, cit., p. 75.

65 Por cierto, como se ha aclarado doctrinariamente (vid. Montoya Melgar, Derecho, cit., p. 471), las ausencias debidas a retenciones ilícitas, como sería el caso de secuestro del trabajador, "no pueden reputarse injustificadas".

${ }^{66}$ Cfr. García Piñeiro, N. P., "Consideraciones sobre la privación de libertad como causa de despido", en Gárate Castro, J. (director), Cuestiones Actuales sobre el despido disciplinario, Ediciones Universidad de Santiago de Compostela 1997, p. 67.

${ }^{67}$ Cfr. Thayer Arteaga y Novoa Fuenzalida, cit., p. 358. Cfr. también sentencia de la CS de 12 de marzo de 1992. GJ N 141 (1992), p. 77; y sentencia de la CS de 2 de noviembre de 1999. RDJ T. XCVI, sec. tercera (1999), p. 225. 
un juzgado del crimen, no importa causa justificada de despido, si no consta, además, que el procesado haya sido condenado, caso en el que debió haberse invocado la causal

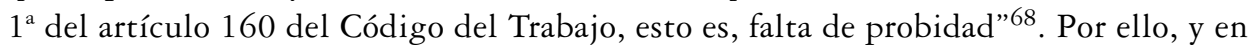
esta misma línea, se ha aceptado que la causa justificante para la inasistencia se radique en un supuesto de fuerza mayor temporal, "siempre que tal privación (de libertad) responda a un acontecimiento imprevisible o previsto, pero inevitable" 69 .

Una segunda postura considera injustificada la inasistencia cuando ella tiene su origen en una detención transitoria derivada de alguna actitud negligente del trabajador $^{70}$. Ello ocurre, por ejemplo, cuando el trabajador es privado de libertad por incumplimiento en el pago de una multa o no pago de pensiones alimenticias. Con todo, si el incumplimiento se fundamenta en una insolvencia del trabajador, se tiende a restarle valor al argumento de que la detención ha tenido su origen en una conducta negligente del trabajador ${ }^{71}$.

Una tercera corriente, por último, ha terminado justificando el despido de un trabajador, fundado en incumplimiento de este, cuando se ve imposibilitado de ejecutar la prestación debida en razón de una conducta culposa socialmente reprochable ${ }^{72}$. La

${ }^{68}$ Vid. sentencia de la CAP de Santiago de 28 de agosto de 2002. GJ No 266 (2002), p. 196.

${ }^{69}$ Vid., García Piñeiro, cit., p. 67; y Montoya Melgar, "El despido”, cit., pp. 95 y ss. Vid., en el plano jurisprudencial, sentencia de la CS de 2 de noviembre de 1999. RFM No 492 (1999), p. 2651: “(...) la ausencia en la que incurrió (el trabajador) resultó plenamente justificada, debido a que se vio impedido de concurrir a prestar los servicios para los que fue contratado, por razones de fuerza mayor. A esta conclusión se arriba, además, teniendo presente que el trabajador fue absuelto de los cargos que se formularon en su contra y que motivaron su privación de libertad (...)"; y sentencia de la CS de 29 de noviembre de 1971 (en especial, en lo que se refiere al Informe emanado por la Corte del Trabajo de Santiago). RDJ T. LXVIII, sec. tercera (1971), p. 98: "(...) la inasistencia de un trabajador por la detención que sea objeto aparece como un caso de fuerza mayor que justifica la ausencia del trabajador".

${ }^{70}$ Vid., en contra, la sentencia de la CS de 6 de abril de 1999. RFM N 485 (1999), p. 555: “(...) el trabajador se ausentó de sus labores entre el 30 de diciembre de 1996 hasta, al menos, el 23 de enero de 1997, tiempo en que se encontraba recluido en el Centro de Detención Preventiva de Ovalle, en virtud de una orden emanada del Primer Juzgado del Letras de esa ciudad, por no pago de pensiones alimenticias, es decir, por orden de autoridad, por lo tanto, dicha ausencia resultó justificada”.

${ }^{71}$ Cfr., Barreiro González, G., Diligencia y negligencia en el cumplimiento. Estudios sobre la prestación del trabajo debido por el trabajador. Centro de Estudios Constitucionales, Madrid 1981, p. 390.

${ }^{72}$ Vid. por ejemplo, sentencia de la CS de 23 de abril de 1986. GJ No 70 (1986), p. 87: "Que, en la especie, la circunstancia de que el demandante no concurriere a sus labores por estar preso en virtud de una encargatoria de reo (...) hace inferir que dicha ausencia fue imputable al trabajador y por ende injustificada (...)”. En igual sentido, sentencia de la CS de 17 de agosto de 2006. RFM N 536 (2005-2006), p. 2213: "Tal justificación -privación de libertad por orden de autoridad competente dispuesta en la investigación que se sigue a su respecto por el delito de conducir vehículo motorizado en estado de ebriedad- debe analizarse de acuerdo con los principios generales del derecho y en el marco del ejercicio de la función jurisdiccional propia de los tribunales, lo que obliga a establecer si procede en la especie la concurrencia jurídica del caso fortuito o fuerza mayor. En la esencia del concepto fuerza mayor o caso fortuito, establecido en el artículo 45 del Código Civil, se hallan la imprevisibilidad y la irresistibilidad del evento a que se ve expuesto el afectado por el caso fortuito o fuerza mayor. En esa situación, la acción voluntaria del trabajador que ha significado que un juez con competencia en lo criminal decida si ha tenido participación en un hecho ilícito, motivo por el cual dispuso su prisión preventiva, puede considerarse como irresistible, por cuanto se trata de la orden de una autoridad, pero no puede calificarse de imprevisible. En efecto, falta en la acción realizada -delito de conducir vehículo motorizado en estado de ebriedad-, la imprevisibilidad que caracteriza al caso fortui- 
sentencia condenatoria firme, en virtud de un procedimiento legalmente tramitado, lleva a concluir que la ausencia del trabajador se debe a una conducta propia, no justificada. De allí que se sostenga que la inasistencia del trabajador radica en su propia conducta negligente, y no en actos de fuerza mayor justificativa ${ }^{73}$.

En síntesis, si el trabajador incumple con su deber de asistencia en virtud de una sentencia condenatoria firme, el empleador estaría facultado para despedir al infractor. Por el contrario, la prisión provisional debiese dar lugar a la suspensión del contrato siempre y cuando se haya comunicado oportunamente al empleador. A la misma conclusión habría que arribar en el caso que el trabajador haya sido absuelto de los cargos imputados o se sobresee la causa en su contra ${ }^{74}$. Por cierto, en todas estas hipótesis se está haciendo referencia a detenciones cuyo origen no radica en acciones eventualmente reconducibles a un incumplimiento grave de las obligaciones. Si así fuese, entonces la detención del trabajador sería un indicio que facilitaría la calificación de la infracción laboral.

\subsubsection{Las vacaciones}

El disfrute de las vacaciones parte de una premisa: el trabajador debe ejercer correctamente este derecho, ya que, en caso contrario, la inasistencia fundada en un uso indebido del feriado justificaría la acción extintiva. De allí que el goce efectivo de las vacaciones requiere de común acuerdo entre las partes en lo que dice relación con la época exacta del ejercicio de este beneficio. Desde luego, no es necesario un acuerdo formal y escrito para disfrutar las vacaciones; pero al menos debe producirse una aquiescencia tácita por parte de ambos contratantes ${ }^{75}$.

to o fuerza mayor, pues lo cierto es que quien ejecuta voluntariamente un acto penado por la ley, puede y debe prever los resultados de esa acción y la posibilidad de ser finalmente encausado y privado de libertad. A lo anterior cabe agregar que no se ha probado en estos autos, por parte del trabajador, la improcedencia del acto de autoridad que lo mantuvo privado de libertad, circunstancia que en su caso, podría modificar la imprevisibilidad a que se ha hecho referencia precedentemente". Criterios similares en sentencia de la CS de 29 de noviembre de 2005. RFM N 539 (2005-2006), p. 3149; sentencia de la CS de 4 de enero de 1995. RDJ T. XCII, sec. tercera (1995), p. 11; y sentencia de la CAP de Santiago de 8 de enero de 1998. GJ No 211 (1998), p. 189.

${ }^{73}$ Cfr. Aguilera Izquierdo, cit., p. 269; y García Piñeiro, cit., p. 68. Ese es el criterio que, por lo demás, se ha seguido en el Derecho comparado como lo acredita el inciso XIV del artículo 47 de la Ley Federal del Trabajo de México, el que considera causa justificada de despido "la sentencia ejecutoriada que imponga al trabajador una pena de prisión que le impida el cumplimiento de la relación de trabajo”. En nuestro país, esta postura ha contado con variado apoyo jurisprudencial. Vid., por ejemplo, sentencia de la CS de 2 de junio de 2009 (Causa Ingreso Corte N ${ }^{\circ}$ 1673-2009); sentencia de la CS de 2 de agosto de 1999. RDJ T. XCVI, sec. tercera (1999), p. 153; y sentencia de la CS de 12 de agosto de 2008. RFM No 550 (2010), p. 467; sentencia de la CAP de Santiago de 11 de mayo de 2004. RFM N 539 (2005-2006), p. 3149; sentencia de la CS de 4 de septiembre de 2003. RFM No 514 (2003), p. 2525; y sentencia de la CS de 2 de agosto de 1999. RDJ T. XCVI, sec. tercera (1999), p. 153.

${ }^{74}$ Vid. García Piñeiro, cit., p. 72. Vid. también Gárate Castro, cit., p. 215.

${ }^{75}$ Cfr. por todos Charro Baena, P., El derecho a vacaciones en el ámbito laboral. Centro de Publicaciones Ministerio de Trabajo y Seguridad Social, Madrid 1993, pp. 468 y ss. Por el contrario, si se ha llegado "a 
La legislación chilena exige que el feriado sea concedido, de preferencia, en primavera o verano, considerándose las necesidades del servicio. Esta norma legal ha generado algunos problemas interpretativos en orden a determinar quién decide el período en el que se hace uso de las vacaciones: (i) Una primera tesis argumentativa estima que el uso del derecho al feriado (así como la determinación del momento exacto en que se ocupará) le corresponde en exclusiva al trabajador. Si él es el titular del beneficio, entonces a él le correspondería determinar cuándo se ausentará de las labores para gozar de las vacaciones (salvo el caso de feriado colectivo); (ii) Un segundo criterio parte de la base que la utilización del feriado se determina de común acuerdo por las partes, o bien considerando las necesidades de la empresa respectiva. De esta manera, el goce del beneficio debe necesariamente ser armonizado con las necesidades generales de la empresa, sin que el trabajador pueda hacer uso automático e inmediato del derecho, salvo que exista acuerdo entre las partes o al menos siempre que se respeten las necesidades generales de la empresa. En virtud de este segundo criterio, el empleador no tiene por qué quedar expuesto a una decisión intempestiva del trabajador en cuanto a la oportunidad en el uso del feriado. Por ello, se estima que en primera instancia el trabajador propone el período en el cual utilizará las vacaciones; pero la empresa podrá proponer otro momento fundado en las necesidades del servicio. Este segundo criterio ha sido formalmente respaldado por la jurisprudencia: "Si bien las disposiciones relativas al feriado solo establecen la obligatoriedad de su otorgamiento y la cantidad de días que comprende, además de algunas reglas para su acumulación, ellas no determinan ni precisan mayores condiciones al respecto, salvo el inciso segundo del artículo 67 del Código del ramo, que prescribe que él 'se concederá de preferencia en primavera o verano'. En este orden de ideas, han de considerarse, también, las expresiones utilizadas por la parte final del inciso y artículo citados, esto es: “(...) considerándose las necesidades del servicio, expresiones que indican, obviamente, que en la concesión del feriado se encuentra involucrada la potestad de mando o administración que posee el empleador en relación con su empresa, siendo este, en definitiva, quien decidirá la época o temporada en que se otorgará el feriado o vacaciones a sus trabajadores" 76 .

\subsubsection{El ejercicio del derecho de huelga}

El ejercicio legal del derecho de huelga provoca la suspensión del contrato de trabajo, y el trabajador tiene derecho a ausentarse justificadamente de sus labores. Así lo establece el artículo 377 del Código del Trabajo, según el cual "durante la huelga o el cierre temporal o lock-out se entenderá suspendido el contrato de trabajo, respecto de los trabajadores y del empleador que se encuentren involucrados o a quienes afecte, en su caso. En consecuencia, los trabajadores no estarán obligados a prestar sus servicios

un acuerdo en materia de vacaciones y este es revocado posteriormente por el empresario, el trabajador no incurre en ausencia injustificada" (cfr. Gil Plana, cit., p. 1459).

${ }^{76}$ Sentencia de la CS de 11 de julio de 2000. RDJ, T. XCVII (2000), p. 131. Vid. también sentencia de la CAP de Copiapó de 30 de noviembre de 1999. RFM Nº 500 (2000-2002), p. 1386. 
ni el empleador al pago de sus remuneraciones, beneficios y regalías derivadas de dicho contrato".

En el sistema normativo chileno, la huelga se circunscribe en un marco de justificación laboral. De esta forma, quedarán fuera de este ámbito aquellas paralizaciones que se basan en elementos diversos al carácter laboral, o que sean una simple expresión del quebrantamiento del orden público. No obstante, la problemática se vuelve más compleja al momento de determinar qué es aquello que debe entenderse como carácter esencialmente laboral de la huelga. En este sentido, la pregunta debiera ir dirigida a la determinación de si la paralización de los trabajadores abarca cualquier problema social; o si bien, el carácter laboral de la huelga se constriñe solo a los intereses profesionales de los trabajadores. Dentro del primer grupo podemos agrupar aquellas huelgas derivadas de recesiones económicas, de acciones de solidaridad con otros grupos de trabajadores, efectos políticos en su sentido amplio, entre otras varias alternativas. Por el contrario, en el segundo grupo deben entenderse inscritas aquellas situaciones derivadas de eventos eminentemente consecuenciales a la relación de trabajo, en que el trabajador es tomado como sujeto activo de la misma y miembro de las relaciones al interior de la empresa. Todo parece indicar que, al menos en el ordenamiento jurídico chileno, la configuración de la huelga se encauza por este segundo camino, más aún si ella solo puede ejercerse en el contexto de la negociación colectiva ${ }^{77}$.

Lo anterior obliga a concluir que las inasistencias fundadas en huelgas fuera del amparo legal no tendrían el nivel de justificación necesario para explicar la ausencia del trabajador. En el fondo, el actual sistema de relaciones laborales en Chile parte de la tesis que no existe huelga fuera de la ley, siendo inválida cualquier otra paralización (o inasistencia) que no tenga su justificación en el ordenamiento jurídico.

\subsubsection{La situación de los trabajadores eximidos de cumplir la limitación de jornada}

Como es sabido, el inciso segundo del artículo 22 CT establece una serie de excepciones a la limitación horaria. Entre ellas se encuentran los trabajadores que presten servicios a distintos empleadores; los gerentes, administradores, apoderados con facultades de administración y todos aquellos que trabajen sin fiscalización superior inmediata; los contratados para prestar servicios en su propio hogar o en un lugar libremente elegido por ellos; los agentes comisionistas y de seguros, vendedores viajantes, cobradores y demás similares que no ejerzan sus funciones en el local del establecimiento. También quedan excluidos los trabajos realizados mediante medios teleinformáticos (teletrabajo) y aquellos en que el trabajador cuente con grados significativos de autonomía y que

${ }^{77}$ Con todo, cabe hacer presente que existen legislaciones que consagran en forma expresa otro tipo de huelgas, permitiendo a los trabajadores solidarizar con sus pares en determinados conflictos. Un ejemplo de ello se encuentra en la Ley Federal del Trabajo de México, cuyo artículo 450, fracción VI, establece como una de las finalidades de esta institución "el apoyar una huelga que tenga por objeto alguno de los enumerados en las fracciones anteriores”. Por otra parte, en Francia, la huelga de solidaridad solamente es legítima cuando tiene el propósito de impugnar y solidarizar con hechos ligados a la relación laboral, ya sea individual o colectiva. 
generalmente se vinculan con la obtención de un resultado. Por cierto, este tipo de trabajadores realiza su actividad fuera de la vigilancia del empleador; pero ello no implica que se encuentren ajenos al poder de organización que este detenta ${ }^{78}$. Más aún, como lo ha destacado la doctrina nacional, este tipo de trabajadores está obligado a concurrir al lugar o sitio donde deban desempeñar sus funciones, sometiéndose a las órdenes del empleador $^{79}$.

En el caso de los trabajadores eximidos de cumplimiento de jornada, la regla general se encamina por la hipótesis que en dichos casos también se producen faltas de asistencia por el simple incumplimiento de las obligaciones por parte del trabajador, "dedicándose durante la jornada laboral a actividades distintas" 80 . A fin de cuentas, este tipo de trabajador está obligado a ejecutar las labores encomendadas y en no pocos casos debe realizar la prestación en aquel lugar que el empleador le ha señalado. Por tanto, la causal extintiva se produciría cada vez que el trabajador deja de desarrollar las actividades dentro del espacio temporal que se le ha exigido ${ }^{81}$.

En algunos casos, no obstante, la jurisprudencia ha sancionado las inasistencias fundadas no en el artículo $160 \mathrm{~N}^{\circ} 3 \mathrm{CT}$, sino que en la causal del artículo $160 \mathrm{~N}^{\circ} 7 \mathrm{CT}$ (incumplimiento grave de las obligaciones que impone el contrato). Si bien en dichas sentencias la trabajadora se encontraba obligada a asistir a reuniones diarias a objeto de recibir instrucciones, la inasistencia a las mismas fue estimada como un claro supuesto de incumplimiento ${ }^{82}$.

\section{La inasistencia durante dos días seguidos}

El Código sanciona en primer término las faltas de asistencia diaria completas ocurridas durante dos días seguidos. Se trata de una infracción directamente vinculada con la prestación de trabajo (a diferencia de otras, que se relacionan con la conducta debida del trabajador en el ámbito de ejecución del contrato $)^{83}$. Como se puede apreciar, el legislador nacional no ha dejado a la simple apreciación judicial la gravedad derivada

${ }^{78}$ Cfr. Baylos Grau, A., "Despido por faltas de asistencia de un trabajador a domicilio", RPS N 133 (1982), p. 214. En el plano jurisprudencial, vid. sentencia de la CS de 13 de mayo de 2010 (Causa Ingreso Corte No 488-2010); y sentencia de la CS de 19 de mayo de 2010 (Causa Ingreso Corte No 715-2010).

${ }^{79}$ Vid. Macchiavello Cúneo, cit., p. 307: "En estos casos, la subordinación se materializará principalmente con las instrucciones y el ejercicio del trabajo en el lugar del empleo, y no con la permanencia obligada durante un cierto curso de la jornada".

${ }^{80}$ Vid. Delgado Ucelay, cit., p. 125.

${ }^{81}$ Eso sucedería, por ejemplo, si existe un régimen flexible de jornada y el trabajador hace abandono transitoriamente del país sin conocimiento del empleador.

${ }^{82}$ Vid. sentencia de la CAP de Santiago de 16 de junio de 1996. RDJ T. XCIII, sec. tercera (1995), p. 128: "El hecho de que la actora no se haya hecho presente en las oficinas de la demandada para asistir a reuniones diarias a objeto de recibir instrucciones, a lo cual estaba obligada por su contrato de trabajo, permite sostener que incurrió en incumplimiento de obligaciones impuestas en su relación contractual". Una situación en parte similar puede consultarse en la sentencia de la CAP de Valparaíso de 2 de marzo de 1994. RDJ T. XCI, sec. tercera (1994), p. 240.

${ }^{83}$ Cfr. Rodríguez Rodríguez, cit., p. 438. 
de una inasistencia reiterada; por el contrario, ha preferido cuantificar la inasistencia a objeto de evitar una calificación discrecional en relación con el número necesario de ausencias para configurar la falta. De esta manera, el Código construye la infracción a base de datos objetivos que permiten determinar la gravedad de la ausencia. Si bien es cierto que la reiteración es un concepto indeterminado ${ }^{84}$, el legislador ha evitado que su precisión se radique en una mera calificación judicial y ha optado por circunscribir el número de inasistencias que sería suficiente para configurar la causal disciplinaria.

En este caso en particular, la conducta prohibida se verifica en una sucesión de actos similares y de la misma entidad, consistentes precisamente en no concurrir a las labores durante dos jornadas laborales completas. El término "día” no se relaciona necesariamente con una acepción astronómica o de medida de tiempo; más bien, la palabra se encuentra estrechamente conectada a la jornada de trabajo convenida con el empleador ${ }^{85}$, y que debe realizarse en un horario determinado durante el día ${ }^{86}$. De allí que doctrinariamente se haya estimado que el "sábado o día equiparable de medio descanso, al comprender la jornada laboral solo la mañana, debe computarse como un verdadero día de trabajo, por referirse a todo el período laboral, aunque sea más corto que en los demás" ${ }^{87}$.

La expresión "días seguidos" por su parte se refiere a dos períodos laborales, y que se estructura en razón del número de horas diarias que conforman el día laboral. Si bien el Código no ha definido la expresión “días seguidos”, ciertamente que mediante ella se pretende hacer referencia a jornadas laborales completas ejecutadas de forma continua, sucesiva, sin intermisión de lugar o tiempo; es decir, sin interrupción de tiempo entre una y otra jornada ${ }^{88}$. Por ello, se ha concluido que no se cumple con la hipótesis de esta causal cuando entre los dos días seguidos ha mediado un día domingo o feriado ${ }^{89}$,

\footnotetext{
${ }^{84}$ Vid., Ortiz Lallana, cit., p. 1127.

${ }^{85}$ Cfr. Gamonal Contreras y Guidi Moggia, cit., p. 284.

${ }^{86}$ Cfr. Delgado Ucelay, cit., p. 126
}

${ }^{87}$ Vid. Delgado Ucelay, cit., p. 126. Vid. también Briones González, cit., p. 327: "La media jornada de los sábados debe considerarse, a estos efectos, como jornada laboral completa, y, consiguientemente, la inasistencia en sábado equivale a inasistencia de una jornada".

${ }^{88}$ Cfr. sentencia de la CS de 19 de junio de 2003. GJ N 276 (2003), p. 206: "La voz 'consecutivo' significa lo que se sigue uno a otro, sin interrupción, es decir, sin contar la continuidad en el tiempo o sin intermisión de tiempo. Igual acepción puede darse a propósito del vocablo 'seguido'. Este es el sentido natural y obvio de estas palabras, según el uso general del mismo, de manera que, ciertamente si ha mediado algún período entre los dos días que se establecen en la norma de análisis, ella no puede ser aplicada, es decir, no se configura la causal de caducidad del contrato (...)".

${ }^{89}$ Cfr., por ejemplo, sentencia de la CAP de Concepción de 4 de octubre de 2002. RFM No 511 (2003), p. 1404: "No se configura la causal de despido aplicada a la trabajadora, por no reunir ella los presupuestos señalados en la ley, ya que esta exige la inasistencia injustificada por dos días seguidos, lo que no ha ocurrido en la especie, en cuanto entre ellos medió el día domingo 23 de diciembre de 2001". Una posición contraria a este criterio, puede consultarse en Davis, P. R., Terminación del contrato de trabajo, Editorial Bibliográfica Chilena, Santiago s/f, pp. 52 y 53, quien con apoyo jurisprudencial concluyó bajo la vigencia de la Ley $\mathrm{N}^{\circ} 16.455$ (de 1966) que esta causal hacía referencia solo a la existencia de dos jornadas sucesivas "(por ejemplo, las de un sábado y un lunes), aunque se interponga entre ambas un día domingo o dos días feriados a su vez seguidos y sucesivos”. 
cuando ha existido un día hábil entre dos inasistencias diarias ${ }^{90}$, o incluso cuando se ha producido la presencia del trabajador a cualquier hora de esos dos días ${ }^{91}$.

Esto obliga a dejar de lado desde ya aquellas ausencias parciales (que eventualmente podrían reputarse como atrasos), pero que no logran computarse como faltas diarias completas, por muy prolongadas que sean ${ }^{92}$. También, en principio, se excluirían del cómputo de los días todas aquellas situaciones en que el trabajador llega al final de la jornada del primer o segundo día y se incorpora a prestar servicios. Más aún, parte de la doctrina ha considerado que en este tipo de supuestos, la pretensión del trabajador de incorporarse tardíamente a las labores (aun cuando el empleador no lo admita) tiene el mérito de enervar la causal de despido ${ }^{93}$. Con todo, hay algunos supuestos que resulta conveniente aclarar. Por ejemplo, la llegada del trabajador una vez terminada la jornada laboral, y ya cerrada la empresa, difícilmente puede enervar el cómputo del plazo. La jornada pactada no ha podido cumplirse y la no prestación del servicio tiene su origen en la exclusiva conducta del trabajador. A la misma conclusión habrá que arribar en caso que el trabajador concurra una vez finalizada la jornada y permanezca en la empresa sin prestar servicio alguno (sobre todo, si se concluye que la falta de asistencia se vincula con la ausencia del trabajador en su puesto de trabajo, durante la jornada convenida ${ }^{94}$ ). Por el contrario, si el trabajador llega a la empresa después de la jornada convenida, y procede a prestar servicios con conocimiento del empleador, entonces ciertamente que no podrá compatibilizarse la inactividad diaria.

También quedarían fuera de la aplicación de esta causal la existencia de una sola ausencia diaria, ya que no se alcanzaría la reiteración exigida por el artículo $160 \mathrm{~N}^{\circ} 3$ $\mathrm{CT}^{95}$. Ello no impide, desde luego, que una sola inasistencia califique como un caso de

${ }^{90}$ Vid. sentencia de la CS de 1 de junio de 1983 (en Thayer Arteaga y Rodríguez Alvarado, cit., p. 329): "La falta de justificación de las inasistencias al trabajo los días domingo 22 y el martes 24 de noviembre de 1981, de un trabajador que tenía labores los días lunes, por no ser seguidos, no configuran en caso alguno, la causal de despido".

${ }^{91}$ Este ha sido el criterio que desde antiguo esgrimió la jurisprudencia laboral. Vid., por ejemplo, la sentencia del Tribunal de Alzada de Santiago de 5 de mayo de 1936. En Repertorio de Legislación y Jurisprudencia Chilenas. Código del Trabajo T. I. Editorial Jurídica de Chile, Santiago 1958, p. 91: "La presencia del empleado, a cualquiera hora de trabajo de esos dos días, sea con el objeto de reanudar sus funciones, sea con el de dar excusas por su inasistencia, determina un abandono del empleo por un plazo inferior a los dos días consecutivos, y es insuficiente para declarar la caducidad del contrato".

${ }^{92}$ La misma lógica seguía la jurisprudencia durante la vigencia del Código del Trabajo de 1931. Vid. por ejemplo, sentencia del Tercer Juzgado del Trabajo de Santiago de 24 de abril de 1930. En Repertorio (1958), cit., p. 14. Igual posición mantenía la doctrina correspondiente al Código de 1931: por todos, Lagos, G., Derecho del Trabajo. Editorial Universitaria, Santiago 1957, p. 375.

${ }^{3}$ Cfr., Macchiavello Cúneo, T. I, cit., p. 520.

${ }^{94}$ Cfr. Rodríguez Rodríguez, cit., p. 439.

${ }^{95}$ Cfr. sentencia de la CS de 28 de agosto de 1997. RFM No 466 (1997), p. 1665: "La ausencia de un solo día de trabajo no configura la causal del art. $160 \mathrm{~N}^{\circ} 3$ del Código del Trabajo". Un criterio distinto, con todo, se ha seguido en el derecho comparado. En EE.UU., por ejemplo, los tribunales de ese país han venido sosteniendo que la absence del trabajador, aunque sea por un solo día, otorga al empleador el derecho a prescindir de sus servicios. Por cierto, se han exceptuado de esta regla aquellas ausencias que tienen su origen en un permiso, cuando el reglamento interno de la empresa exige un cierto número de faltas, o bien 
incumplimiento grave de las obligaciones (Art. $160 \mathrm{~N}^{\circ} 7 \mathrm{CT}$ ), sobre todo si se toma en cuenta la especial función que el trabajador cumplía al interior de la empresa. Así ocurriría, por ejemplo, en el caso de trabajadores que desempeñan funciones de responsabilidad o bien que se refiera a un único trabajador a cargo del establecimiento. Aun cuando se trate de una sola inasistencia, lo más probable es que la ausencia provoque un perjuicio relevante que permitiría invocar la causal de incumplimiento grave de las obligaciones o incluso la figura regulada en la segunda parte del artículo $160 \mathrm{~N}^{\circ} 3 \mathrm{CT}^{96}$.

Por último, cabe hacer presente que la exigencia de dos días seguidos permite concluir, además, que la falta es objetiva (más allá de si procede o no aplicarla automáticamente) ${ }^{97}$. Por tanto, en la aplicación de esta causal no resulta necesario acreditar un dolo específico y tampoco la existencia de perjuicios especiales ${ }^{98}$. En el fondo, el legislador concluye que reviste gravedad suficiente para el despido la inasistencia durante dos días consecutivos. Lo que ocurre es que la repetición de la falta evidencia un mayor desprecio del infractor hacia los bienes protegidos ${ }^{99}$, cuestión que reafirma la gravedad legalmente asignada al hecho.

\section{La inasistencia durante dos lunes en el mes}

En sus orígenes, la consagración de este específico tipo infraccional se justificaba en razón de la gravedad que se le asignaba a la inasistencia en un día lunes, cuestión "frecuente en nuestros obreros en ese día en que suelen prolongarse las fiestas del domingo o repercutir los excesos de ellas" ${ }^{100}$. Lo que se pretendía, en el fondo, era evitar una indisciplina laboral que impidiese la obligación principal del trabajador, cual es la de "trabajar"101, dejando de lado una vieja costumbre relacionada con el denominado "San Lunes”, en cuya virtud el ausentismo laboral se hacía más creciente durante el primer día de la semana.

Por razones culturales, y de cierta inercia legislativa, esta falta se mantuvo en los textos laborales por todo el siglo XX. Y nos llega hasta hoy como una expresión más de la gravedad de las faltas vinculadas a la inasistencia ${ }^{102}$. Con todo, su actual mantención

cuando la ausencia tiene su origen en motivos justificados. Sobre el particular, vid. Martínez Girón, J., El despido en el Derecho de los Estados Unidos, Civitas, Madrid 1988, p. 75.

96 Vid. la postura planteada por Gómez Abelleira, "Las causas disciplinarias”, cit., p. 186, en relación con un caso del derecho comparado. Según este autor, una sola inasistencia no es suficiente para justificar el despido, "salvo que ese incumplimiento resulte cualificado por los perjuicios que irroga, o resulte acompañado de notas de desobediencia o de mala fe, engaño, fraude o deslealtad (...)”.

${ }^{97}$ Sobre la imposibilidad de que este tipo de causales opere ipso facto, vid. sentencia de la CS de 17 de mayo de 1991. RDJ T. LXXXVIII, sec. tercera (1991), p. 45.

${ }^{98}$ Respecto de la eventual necesidad de que concurran perjuicios en relación con este tipo de causales, cfr. Sagardoy Bengoechea, J. A., El despido laboral y los expedientes de crisis, Ediciones Deusto, Bilbao 1969, p. 73.

${ }^{99}$ Cfr. Fernández López, cit., p. 207.

${ }^{100}$ Cfr. Escribar Mandiola, H., Tratado de Derecho del Trabajo, Zig-Zag, Santiago, 1944, pp. 376 y 377.

${ }^{101}$ Cfr. Walker Errázuriz, F., Terminación del contrato de trabajo. Cepet, Santiago, 1990, p. 57.

102 Parte de la doctrina nacional (vid. Walker Errázuriz, Terminación, cit., p. 57) ha cuestionado la pertinencia de este tipo de redacciones, sobre todo si se consideran las modificaciones que ha sufrido el 
en el Código se explica por un simple análisis histórico de esta norma. En efecto, las primeras leyes sociales establecían esta causal para el caso de los obreros bajo el argumento de que, en el sector de la construcción o en el ejercicio de actividades manuales, resultaban más usuales las ausencias durante ese específico día de la semana. Más aún, y sobre todo en la etapa de aplicación del modelo clásico del trabajo subordinado, las mayores ausencias se producían en el día lunes, para ir decreciendo en el curso de la semana ${ }^{103}$. Con la llegada de la Ley $\mathrm{N}^{\circ} 16.455$, la causal pasó a incorporarse como un supuesto genérico de inasistencia aplicable a todo tipo de trabajador, estimándose más grave la ausencia un día lunes que en otro día de la semana, básicamente por la mayor frecuencia que representa la ausencia durante ese día ${ }^{104}$.

En los últimos años, no obstante, estudios especializados se han encargado de reafirmar el mayor nivel de ausentismo durante los días lunes. Una prueba de ello es el Informe Final de la Comisión Asesora Presidencial para la Seguridad en el Trabajo, de noviembre de 2010, el que concluyó que, al menos en el sector de la construcción, "el ausentismo laboral se produce reiteradas veces los días lunes"105.

\section{La inasistencia durante tres días en el mes calendario}

Por último, la primera parte del artículo $160 \mathrm{~N}^{\circ} 3 \mathrm{CT}$ sanciona las inasistencias ocurridas durante tres días en el mes. En este caso, la gravedad de la ausencia está caracterizada por varios actos de inasistencia que, analizados de forma aislada cada uno de ellos, reúne todas las características de una infracción, pero que se califican globalmente como un solo todo ${ }^{106}$. De esta forma, lo que termina sancionando el Código, al exigir tres faltas de concurrencia, es la continuidad de una conducta consistente en no asistir al trabajo.

La expresión "mes", al igual que en los casos anteriores, hace referencia a un mes calendario y no a 30 días determinados ${ }^{107}$. De esta forma, el cómputo debe hacerse en

mercado laboral: “(...) su norma es bastante arcaica y corresponde, en cierto modo, a una realidad laboral pretérita”. El mismo planteamiento han formulado Gamonal Contreras y Guidi Maggio, cit., p. 286, quienes consideran arcaico este tipo de normas, ya que "prevé influenciar las actividades del trabajador durante el fin de semana, en orden a abstenerse del consumo excesivo de alcohol, que eventualmente podía influir en su ausentismo el día lunes".

${ }^{103}$ Cfr., Behrend, cit., p. 130. En el estudio de que da cuenta este artículo, elaborado hacia la mitad del siglo XX, esta autora construyó un índice de ausencias en días lunes, concluyendo que efectivamente el absentismo era mayor durante el primer día de la semana. Ese mismo estudio concluía que el absentismo tenía mayor frecuencia después de una interrupción del trabajo; y que, en el caso de jornadas labores distribuidas en cinco días y medio, "se registra un nuevo máximo de ausencia el sábado".

${ }^{104}$ Cfr. Cabanellas, cit., T. II Vol. 3, p. 170.

$105 \mathrm{Vid}$. este Informe en http://www.comisionseguridadeneltrabajo.cl/wpcontent/uploads/downloads/2010/12/Informe-Final-CST.pdf.

106 Cfr. en el plano doctrinario González Ortega, cit., p. 251.

107 Cfr. Domínguez Errázuriz, M., Manual para la aplicación de la Ley $N^{\circ} 16.455$ y su reglamento sobre inamovilidad en el empleo. Edilex, Santiago, s/f, pp. 18 y 19. 
relación con alguna de las 12 mensualidades del año. Asimismo, la expresión día debe ser vinculada con la jornada convenida entre trabajador y empleador, la que debe realizarse en un horario determinado durante los días de la semana.

Coincidentemente con la hipótesis sancionadora analizada en el punto anterior, la norma tiene una sólida raigambre histórica y se justifica como una manera de evitar que el trabajador haga un hábito de las inasistencias salteadas y esparcidas durante el mes calendario.

\section{Conclusiones}

1. El punto central en la configuración de las inasistencias, como causa de despido, es el de la justificación. Para dicho efecto, las ausencias temporales del trabajador serán admisibles cada vez que exista algún precepto legal, reglamentario o circunstancias racionales que disculpen la no asistencia.

2. Los criterios de justificación han tenido una mirada amplia y más bien flexible por parte de la jurisprudencia. En la práctica, los tribunales han terminado aceptando un cúmulo de supuestos de hecho que, caracterizados por la racionalidad, permiten exculpar de responsabilidad al trabajador. Con todo, parte importante de la atención jurisprudencial se ha centrado en supuestos como la detención o el otorgamiento de licencias médicas. En el primer caso, la evolución jurisprudencial le ha restado fundamento a las inasistencias fundadas en una detención previa del trabajador, ya que dicha privación de libertad ha tenido su origen en una conducta culposa socialmente reprochable. Más aún, para la jurisprudencia la inasistencia del trabajador radica en su propia conducta negligente, y no en actos de fuerza mayor justificativa. Respecto de las licencias médicas, la corriente mayoritaria ha exhibido una mayor flexibilidad fundada en la doctrina de la culpabilidad y poniendo el acento en la existencia de una verdadera enfermedad más que en el cumplimiento de las formalidades de comunicación de la licencia.

3. En la primera hipótesis del artículo $160 \mathrm{~N}^{\circ} 3 \mathrm{CT}$, la gravedad de la conducta infraccional ha sido tasada por el legislador, en el sentido que la ley ha determinado con exactitud el quantum de los días de inasistencia. En este escenario, la labor del juzgador queda reducida fundamentalmente a evaluar la justificación, pero no a determinar el número de veces en que la inasistencia diaria sería realmente grave. Por el contrario, en la segunda parte del artículo $160 \mathrm{~N}^{\circ} 3$ CT la gravedad admite un mayor margen de evaluación por parte del juez, ya que lo relevante es la existencia de una perturbación de cierta entidad que solo puede calificarse a partir de ciertos supuestos de hecho. 


\section{BIBLIOGRAFÍA}

Aguilera IzQuierdo, R., Las causas del despido disciplinario y su valoración por la jurisprudencia, Aranzadi, Pamplona, 1997.

Alonso García, M., Curso de Derecho del Trabajo, Ariel, 10ª edición, Barcelona, 1987.

Alonso Olea, M., El despido, Instituto de Estudios Políticos, Madrid, 1958.

Barreiro González, G., Diligencia y negligencia en el cumplimiento. Estudios sobre la prestación del trabajo debido por el trabajador, Centro de Estudios Constitucionales, Madrid, 1981.

Baylos Grau, A., "Despido por faltas de asistencia de un trabajador a domicilio", RPS No 133 , 1982.

Behrend, H., "La ausencia voluntaria del trabajo”, RIT Vol. LIX, 1959.

Briones GonZÁlez, C., La extinción del contrato de trabajo por causas objetivas, Centro de Publicaciones Ministerio de Trabajo y Seguridad Social, Madrid, 1995.

Cabanellas, G., Tratado de Derecho Laboral, T. II Vol. 3, Heliasta, $3^{a}$ edición, Buenos Aires, 1988.

Charro Baena, P., El derecho a vacaciones en el ámbito laboral, Centro de Publicaciones Ministerio de Trabajo y Seguridad Social, Madrid, 1993.

Davis, P. R., Terminación del contrato de trabajo, Editorial Bibliográfica Chilena, Santiago s/f.

Del Peso y Calvo, C., "Las faltas repetidas e injustificadas de puntualidad o de asistencia al trabajo como causa justa de despido". Dieciséis lecciones sobre causas de despido. Sección de Publicaciones e Intercambio Facultad de Derecho Universidad de Madrid, Madrid, 1969.

Delgado Ucelay, I., "Faltas repetidas e injustificadas de asistencia al trabajo", Estudios sobre el despido disciplinario, Acarl, Madrid, 1992.

Domínguez Errázuriz, M., Manual para la aplicación de la Ley $N^{o} 16.455$ y su reglamento sobre inamovilidad en el empleo, Edilex, Santiago, s/f.

Durán López, F., "La prescripción de las faltas de asistencia o puntualidad del trabajador tras la Ley de Relaciones Laborales", RPS No 117, 1978.

Edwards IzQuierdo, I., Deberes del empleador frente al empleado, Ediciones Ercilla, Santiago, 1939.

Escribar Mandiola, H., Tratado de Derecho del Trabajo, Zig-Zag, Santiago, 1944.

FernÁndez López, M.F., El poder disciplinario en la empresa, Civitas, Madrid, 1991.

Gamonal Contreras, S., y Guidi Moggia, C., Manual del contrato de trabajo, AbedeloPerrot/ LegalPublishing, $2^{\mathrm{a}}$ edición, Santiago, 2011.

GÁrate Castro, J., "Las faltas de asistencia o puntualidad como incumplimiento contractual justificativo de despido disciplinario", RPS No 129, 1981.

García Murcia, J., "Falta de diligencia y transgresión de la buena fe contractual" (I y II), AL $\mathrm{N}^{\circ} 25$.

García Piñeiro, N. P., "Consideraciones sobre la privación de libertad como causa de despido", en Gárate Castro, J. (director), Cuestiones Actuales sobre el despido disciplinario, Ediciones Universidad de Santiago de Compostela, 1997.

Gil Plana, J., "Las faltas repetidas e injustificadas de asistencia o puntualidad al trabajo como causa de extinción de los contratos", AL No 1, 2005.

Gómez Abelleira, F. J., "Las causas disciplinarias del despido", en Sempere Navarro A. V. (director), El despido, Aranzadi-Thomson Reuters, $2^{a}$ edición, Pamplona, 2009.

Gómez Abelleira, F. J., La causalidad del despido disciplinario, Civitas/Thomson Reuters, Madrid, 2009.

GonzÁlez Ortega, J., "Faltas de asistencia o puntualidad al trabajo; la repetición de las faltas y la aplicación del principio non bis in idem”, RPS No 139, 1983.

Lagos, G., Derecho del Trabajo. Editorial Universitaria, Santiago, 1957.

Lizama Portal, L., Derecho del Trabajo, LexisNexis, Santiago, 2003. 
Macchiavello Cúneo, G., Derecho del Trabajo T. I, Fondo de Cultura Económica, Santiago, 1986. Martínez Girón, J., El despido en el Derecho de los Estados Unidos, Civitas, Madrid, 1988.

Mesa M., F.R., y KaempfFer R., A.M., "30 años de estudio sobre ausentismo laboral en Chile: una perspectiva por tipos de empresas”, RMCH Vol. $132 \mathrm{~N}^{\circ}$ 9, 2004.

Montoya Melgar, A., Derecho del Trabajo. Tecnos, 29ª edición, Madrid, 2008.

Montoya Melgar, A., "El despido por fuerza mayor”, RPS No 85, 1970.

Ortiz Lallana, M.C., "Causas y formas del despido disciplinario (en torno a los artículos 54 y 55)", en El Estatuto de los Trabajadores veinte años después. Civitas, Madrid, 2000.

Repertorio de Legislación y Jurisprudencia Chilenas. Código del Trabajo y Leyes Complementarias, T. I. Editorial Jurídica de Chile, Santiago, 2002.

Repertorio de Legislación y Jurisprudencia Chilenas. Código del Trabajo T. I. Editorial Jurídica de Chile, Santiago, 1958.

Rodríguez Rodríguez, E., "Las faltas de asistencia o puntualidad al trabajo como infracción disciplinaria: su regulación convencional", AFDO N ${ }^{\circ} 1,2006$.

Rojas MiÑo, I., Manual de Derecho del Trabajo, LexisNexis, Santiago, 2004.

Sagardoy Bengoechea, J. A., El despido laboral y los expedientes de crisis, Ediciones Deusto, Bilbao, 1969.

Thayer Arteaga, W., y Novoa Fuenzalida, P., Manual de Derecho del Trabajo, T. III. Editorial Jurídica de Chile, $3^{a}$ edición, 1998.

Thayer Arteaga, W., y Rodríguez Alvarado, A., Código del Trabajo y Legislación Social, Editorial Jurídica de Chile/Editorial Jurídica Ediar Cono-Sur Ltda., Santiago, 1988.

Walker Errázuriz, F., Derecho de las Relaciones Laborales, Editorial Universitaria, Santiago, 2003.

Walker Errázuriz, F., Terminación del contrato de trabajo. Cepet, Santiago, 1990. 
